Published in final edited form as:

Curr Gene Ther. 2010 October ; 10(5): 319-340.

\title{
AAV's Anatomy: Roadmap for Optimizing Vectors for Translational Success
}

\author{
Angela M. Mitchell ${ }^{\# 1,2}$, Sarah C. Nicolson ${ }^{\# 1,3}$, Jayme K. Warischalk ${ }^{\# 1,3}$, and R. Jude \\ Samulski ${ }^{1,3,}$, \\ ${ }^{1}$ UNC Gene Therapy Center, University of North Carolina at Chapel Hill, Chapel Hill, North \\ Carolina, USA \\ ${ }^{2}$ Department of Microbiology and Immunology, University of North Carolina at Chapel Hill, Chapel \\ Hill, North Carolina, USA \\ ${ }^{3}$ Department of Pharmacology, University of North Carolina at Chapel Hill, Chapel Hill, North \\ Carolina, USA \\ \# These authors contributed equally to this work.
}

\begin{abstract}
Adeno-Associated Virus based vectors (rAAV) are advantageous for human gene therapy due to low inflammatory responses, lack of toxicity, natural persistence, and ability to transencapsidate the genome allowing large variations in vector biology and tropism. Over sixty clinical trials have been conducted using rAAV serotype 2 for gene delivery with a number demonstrating success in immunoprivileged sites, including the retina and the CNS. Furthermore, an increasing number of trials have been initiated utilizing other serotypes of AAV to exploit vector tropism, trafficking, and expression efficiency. While these trials have demonstrated success in safety with emerging success in clinical outcomes, one benefit has been identification of issues associated with vector administration in humans (e.g. the role of pre-existing antibody responses, loss of transgene expression in non-immunoprivileged sites, and low transgene expression levels). For these reasons, several strategies are being used to optimize rAAV vectors, ranging from addition of exogenous agents for immune evasion to optimization of the transgene cassette for enhanced therapeutic output. By far, the vast majority of approaches have focused on genetic manipulation of the viral capsid. These methods include rational mutagenesis, engineering of targeting peptides, generation of chimeric particles, library and directed evolution approaches, as well as immune evasion modifications. Overall, these modifications have created a new repertoire of AAV vectors with improved targeting, transgene expression, and immune evasion. Continued work in these areas should synergize strategies to improve capsids and transgene cassettes that will eventually lead to optimized vectors ideally suited for translational success.
\end{abstract}

\section{Keywords}

Adeno-associated virus; clinical trials; directed evolution; gene delivery; immune response; capsid modification; targeting

\footnotetext{
(C) 2010 Bentham Science Publishers Ltd.

*Address correspondence to these authors at the UNC Gene Therapy Center, University of North Carolina at Chapel Hill, 7119 Thurston Bowles Building, (104 Manning Drive), Campus Box 7352, Chapel Hill, NC 27599-7352; USA; Tel: 919.962.3285; Fax: 919.966.0907; rjs@med.unc.edu,.
} 


\section{INTRODUCTION}

Gene therapy has the potential to cure genetic diseases and to allow the long-term, noninvasive treatment of acquired diseases in humans. Through therapeutic gene transfer, genetic diseases could be cured by gene addition, addition of a functional copy of the defective gene, while, acquired disease could be treated by the introduction of genes to synthesize therapeutic proteins or encoding of therapeutic RNAs (shRNA). Worldwide, approximately 1500 gene therapy clinical trials have been approved to date and, although the majority are phase I trials, approximately four percent are phase III trials. These trials are focused on many areas of disease including monogenetic disease, cancer, cardiovascular disease, neurological diseases, and ocular disease (wiley.co.uk/genetherapy/clinical). With the promising results of initial clinical trials, understanding of the various strategies for gene delivery and of the design of vectors to improve clinical efficacy has become increasingly important. In this review, we will discuss the potential of Adeno-Associated Virus vectors (rAAV) as a gene delivery vector, including rAAV's current clinical use and new strategies to create better AAV vectors and increase the efficacy of rAAV based gene therapy. Gene delivery strategies can be generally divided into the categories of non-viral and viral strategies.

\subsection{Non-Viral Gene Delivery Strategies}

Non-viral strategies can include chemical techniques, such as the use of "naked" nucleic acid and the use of cationic carriers, and more biological carriers, such as biologic membranes, bacteria, and virus-like particles (VLPs). The simplest strategy for gene transfer is the use of naked nucleic acids and several studies have examined the uses of naked DNA [1] or RNA [2] for in vivo gene delivery. Although this technique has the advantage of simplicity, unprotected nucleic acids are generally impractical for in vivo use due to rapid degradation, low transfection levels, and lack of tissue targeting ability; however, delivery methods such as hydrodynamic injection can increase the success rate [3].

An additional, more complex, chemical strategy for the gene delivery is the use of cationic lipid or polymer carriers to deliver nucleic acids in a more efficient manner. Some of the recent advances with these techniques have been reviewed [4-6]. Many of these carriers were adapted for in vivo use in order to avoid early problems with viral vectors, such as immune responses and toxicity; however, cationic carriers generally suffer from low efficiency of transfection. One problem that has occurred with cationic carriers is an inability to control the condensation state of the DNA, leading to decreased stability and decreased transcriptional activity of the delivered DNA [7]. Strategies to increase the uniformity of DNA condensation include the creation of non-uniform polymers and the use of a mix of polymers. In addition, cationic complexes generally promiscuously bind to proteins, leading to very low circulation times in vivo. Although the addition of polyethylene glycol (PEG) to the complexes (PEGylation) can increase circulation times, this generally leads to lower gene expression than is observed with non-PEGylated complexes [8]. Furthermore, cationic complexes have no ability to target specific tissues. Targeting ligands can be added to the complexes; however, can increase immune responses and change in intracellular trafficking [9]. Finally, the cationic carriers do not avoid innate immune responses by DNA sensors and can lead to long-term changes in cellular gene expression and differentiation profiles [10]. For all of these reasons, more biological gene delivery systems have been sought.

Several biological, non-viral gene delivery systems, including bactofection, biological liposomes, and virus-like particles, have now been developed and have been more rigorously reviewed [11]. Bactofection utilizes attenuated bacteria to deliver DNA, mRNA, or a therapeutic protein to its host cell [12-14]. The advantages of bactofection include the 
rapid and inexpensive production of many species of bacteria, wide variety in tropism, accommodation of multiple types and sizes of "genetic cargo", strategies of immune evasion, and control by antibiotics. Nevertheless, this strategy often leads to low levels of transgene expression [15], immune responses to conserved molecular motifs, toxicity [12, 15], and the production of inhibitory antibodies [16], as well as the possibility of preexisting immunity to the bacterial vector.

Other biological carriers that have been considered for in vivo gene delivery are biological liposomes such as erythrocyte ghosts and secretion exosomes. The liposomes can be derived from the subject to be treated to avoid immune responses; however, this also inhibits largescale production, as carriers for each subject would need to be made individually. Further advantages of biological liposomes include easy loading of nucleic acid cargo [17] and high stability [18]. However, these carriers have limited endothelial permeability and are in very early stages of development.

One final non-viral gene delivery strategy is the use of virus-like particles (VLP), or empty viral particles. VLPs are produced by transfecting cells with only the structural genes of a virus and harvesting the empty particles. The particles can then be loaded ex vivo with normal or modified nucleic acids, such as locked nucleic acid (LNA) [19]. In addition, VLPs are generally easier to purify than their genome containing parent virus [20]. These particles generally exhibit the same characteristics as their parent virus; however, low loading efficiency and strong immune responses $[21,22]$ hinder their practical application for gene therapy.

\subsection{Viral Gene Delivery Strategies}

The difficulties with non-viral gene delivery systems in vivo highlight the importance of viral gene delivery systems (viral vectors) for clinical gene therapy. At least sixteen different viruses are being used for gene delivery in clinical trials; however, viruses used for gene delivery can be separated into several categories: non-mammalian viruses, oncolytic mammalian viruses, and general mammalian viruses. The two most common types of nonmammalian viruses used for gene delivery are Baculoviruses and bacteriophage.

Baculoviruses' natural hosts are insects, but these viruses can transduce mammalian cells and have a long-standing history of use in vitro [23]. These vectors can accommodate large transgenes, have easily scalable production, are not replica-tive in mammalian cells and are not toxic [24], have no preexisting immunity in humans [25], and can transduce stem cells [26]. Unfortunately, Baculovirus vectors tend to elicit strong innate and adaptive immune responses [27], are inactivated by the complement serum proteins [28], elicit some viral gene expression [29], allow for only transient transgene expression [30], and have demonstrated limited efficacy in vivo [30,31]. Thus, although Baculoviruses are highly efficient vectors in vitro, they require further development to exploit their full potential for in vivo use. Bacteriophage, on the other hand, tend to be highly stable [32], be nonpathogenic to eukaryotic cells [33], have flexible packaging capacities [34], allow the use of targeting ligands [35], and be easy and inexpensive to produce. However, these vectors tend to degrade quickly in vivo [36] and are highly immunogenic [33]. Until these critical issues are resolved, mammalian viruses may be better options for in vivo gene delivery, as they have evolved to be successful in mammalian environments.

An area of increasing clinical interest is the use of gene therapy to treat cancer. One strategy to target gene therapy to cancer cells employs an oncolytic virus to deliver a transgene to enhance tumor cell cytotoxicity; these viruses have been recently, thoroughly reviewed [37, 38]. Oncolytic viruses have a natural cytotoxicity to cancer cells and their selectivity for these cells is often enhanced by mutations that inhibit their replication in other cell types. In addition, the insertion of cytotoxic transgenes, such as Herpes Virus thymidine kinase, into 
these viruses can greatly enhance their killing of cancer cells [39]. Specifically, viruses with the capacity to be oncolytic include Herpes Simplex Virus [40], Adenovirus [41, 42], Reoviruses [43], Vesicular Stomatitis Virus [39] and Measles Virus [44, 45]. In fact, an Adenovirus vector has been approved as a therapeutic for head and neck cancer in China [46]. Furthermore, a Reovirus vector called Reolysin ${ }^{\circledR}$ [47] marketed by Oncolytic Biotech, Inc was recently approved for phase III clinical trials in the UK and the USA. The use of oncolytic viruses for gene delivery is a very beneficial strategy for cancer gene therapy; however, other strategies are necessary for other gene therapy applications.

The final category of viral gene delivery vectors are general mammalian viral vectors, the most common of which are Adenovirus, lentiviruses, and Adeno-Associated Virus (AAV). Adenovirus was developed early as a gene delivery vector and is still the most common vector used for gene therapy clinical trials. The use of adenovirus as a gene delivery vector has been thoroughly reviewed [48]. Adenoviral vectors have the advantages of efficient transduction of dividing and non-dividing cells, high transgene capacity, high stability in blood, and low insertional mutagenesis rates. However, they are highly immunogenic and inflammatory, are subject to preexisting immunity, and are generally diverted from circulation to the liver [48]. The high inflammatory reaction and immunogenisity make these viruses ideal for cancer immunotherapy and vaccine applications. Another very commonly used class of mammalian viruses for gene therapy is lentiviral vectors based on complex retroviruses such as HIV or SIV [49]. These viruses can transduce non-dividing cells [50], permit pseudotyped (packaged into an envelope containing proteins of another virus) [51], and demonstrate less tendency to integrate into transcriptionally active genes than other retrovirus [52]. Conversely, lentiviral vectors still demonstrate the possibility of insertional mutagenesis [53], are subject to transgene silencing and variation due to integration site [54], are subject to innate immune responses and to preexisting immunity to the pseudotyped proteins [55], lack scalable production, and have difficulties with appropriate animal models [56]. However, lentiviral vectors have been successfully applied to the treatment of X-linked adrenoleukodystrophy (ALD) through ex vivo transduction of hematopoietic stem cells in a phase I clinical trial [57]. Through ex vivo transfer, cells can be screened for vector integration sites. In addition, integration deficient viruses are currently in development $[58,59]$. This result demonstrates the great promise of lentiviral vectors.

Another common mammalian viral vector is Adeno-Associated Virus, which will be discussed in the remainder of this review. AAV is not associated with any disease or pathology and is non-inflammatory and non-toxic in humans [60]. In addition, this virus naturally persists in many tissues, allowing for long-term transgene expression [61]. Furthermore, the ability to package AAV serotype 2 (AAV2) based transgenes in capsids from a variety of serotypes (transencapsidation) creates vectors with widely varied tropism [62]. All of these factors make AAV an ideal vector for gene therapy.

\subsection{Adeno-Associated Virus Biology}

AAV was first discovered as a contaminating virus in stocks of Adenovirus [63]. This virus was later classified as a member of the family Parvoviridae and, as it cannot replicate without the presence of a helper virus, a member of the Dependovirus genera. Since the initial discovery of AAV, many different serotypes of AAV, having between $49 \%$ and $99 \%$ identity in capsid protein amino acid sequence, have been isolated within human tissues and within the tissues of many other animals [64]. Although the most commonly used serotype in clinical trials to date is AAV2, several other sero-types are becoming more prevalent, including AAV1, AAV6, AAV8, and AAVrh.10, an AAV isolated from rhesus macaques. 
The AAV genome consists of a linear $4.7 \mathrm{~kb}$ single-stranded DNA molecule that can be either positive or negative sense. Inverted terminal repeats (ITRs), present at both ends of the genome, serve as an origin of replication for the viral DNA and as integration elements [65]. In addition, the genome consists of two genes, Rep and Cap, that, together, encode for seven proteins. The Rep gene encodes the four non-structural proteins of the virus-Rep78, Rep68, Rep52, and Rep40 - through alternative promoters and splicing vari ants. The functions of the Rep proteins include genome replication, transcriptional control, integration, and genome encapsidation [66, 67]. Although it is known that the large Reps (Rep78 and Rep68) function in the nicking and unwinding of the ITRs, the functions of the small Reps (Rep52 and Rep40) are not yet clear. The other gene, Cap, encodes the structural proteins of the virus-VP1, VP2, and VP3 - through splicing and start codon variants. VP1, VP2, and VP3, all share the common VP3 region, while VP1 and VP2 have additional N-terminal regions. These proteins combine to form the viral capsid. AAV is a non-enveloped virus with an icosahedral $(\mathrm{T}=1)$ capsid of approximately 20 to $30 \mathrm{~nm}$. Capsid structures have been solved for eight serotypes of AAV: AAV1 [68], AAV2 [69], AAV4 [70], AAV5 [71], AAV6 [72], AAV7 [73], AAV8 [74], and AAV9 [75]. The three capsid proteins combine to form the capsid in a ratio of VP1:VP2:VP3 of 1:1:10 [69]; therefore, each capsid contains fifty copies of VP3 and 5 copies each of VP1 and VP2. The genome is thought to be packaged into the preassembled capsid in the nucleus [76], through a pore located at the fivefold axis of symmetry.

Although latent infection with AAV is very common in the human population, no pathogenesis has ever been linked with AAV [61]. When AAV encounters a host cell, it is subject to phagocytosis through receptor-mediated endocytosis [77]. The capsid must then escape from the endosome and be transported to the nucleus, where uncoating occurs [78]. In addition to the common region shared by all three capsid proteins, VP1 and VP2 both contain nuclear localization signals (NLS) required for the nuclear transport of the capsid $[79,80]$. Furthermore, VP1 contains a phospholipase domain, which is thought to be required for the endosomal escape of the virion [80]. After the capsid releases the genome, the genome must then be converted to double stranded form by Rep and cellular DNA synthesis machinery [81]. As AAV is a non-autonomous virus, it cannot replicate without a helper-virus functions present in the same cell. In the absence of a helper, AAV DNA can be retained in circular episomal form [82] or can be integrated into the chromosome at the AAVS1 integration site [83, 84]. The episomal and integrated DNA are both found in ITR mediated concatemerized form. In the presence of a helper virus or cellular stress, AAV transcription and DNA replication are reactivated and AAV completes its replication cycle.

Various helper viruses have been identified for AAV including Adenovirus [63], Herpes Simplex Virus [85], Vaccinia virus [86], and Human Papillomavirus [87, 88]. In addition, several chemicals, such as hydroxyurea [89] and carcinogens, such as UV light in the presence of SV40 T antigen [90], can take the place of a helper virus in allowing productive replication of AAV. The helper virus is necessary for and increases the efficiency of several essential functions of AAV. Helper viruses can facilitate nuclear transport of AAV [91], double stranded DNA formation [81, 92], and the conversion to circular DNA [93, 94]. Helper viruses also activate AAV transcription by releasing the $\mathrm{p} 5$ promoter from Rep mediated repression [95-97]. Furthermore, the helper viruses increase the splicing [98], transport [99], stability [100], and translation [100] of AAV mRNAs. Finally, the helper virus facilitates the replication of the AAV genome [101-103] and cell escape [104]. Thus, an active infection involves helper viral or chemical components in addition to the AAV viral machinery. 


\subsection{AAV as a Gene Therapy Vector}

AAV is readily adaptable as a gene therapy vector. In order to use AAV to deliver genes, the transgene is substituted for the coding sequence for both AAV genes and placed between the ITRs. The ITRs are the only element of the AAV genome required in cis for packaging and viral assembly [105]. When producing rAAV, the viral genes and Adenovirus genes providing helper functions to AAV are supplied in trans to allow for production of the rAAV particles. In this way, rAAV is produced through a three-plasmid system, decreasing the probability of production of wildtype virus [106]. Additionally, genomes containing AAV2 ITRs can be transencapsidated into capsids of various serotypes, which have differing receptor binding and intracellular trafficking properties [62]. This allows for the production of AAV with widely varying tropism. Furthermore, self complementary rAAV genomes (scAAV) are available with a mutated ITR that Rep cannot nick, facilitating the packaging of a double stranded genome [107]. scAAV avoids the rate-limiting step of conversion of the single stranded genome to a double stranded, transcriptional active form and increases transcription kinetics [108]. Because of the flexibility of rAAV vectors, AAV represents a promising and versatile viral vector for gene therapy.

rAAV is generally thought to navigate the same intracellular trafficking pathway as wildtype AAV; however, rAAV presents a different genome integration pattern than wild type AAV due to the lack of Rep. As integration at AAVS1 is specific and dependent on Rep, rAAV forms episomes or integrates at low frequency at sites throughout the human genome [109]. Most of the integrated DNA, as well as the episomal DNA, is present in the form of head to tail concatemers, similar to wildtype AAV genomes [110]. Integration events seem to involve recombination between the ITRs and the host DNA leading to integration of the rAAV genome and a small deletion of host DNA [111]. Although this integration can occur throughout the host genome, $\mathrm{CpG}$ islands and ribosomal DNA repeats seem to be common sites of integration [111]. Although a insertional mutagenesis is a possible negative consequence of integration, the integration of the rAAV genome may allow for long-term persistence of transgene expression, even in a dividing cell, emphasizing AAV's promise as a gene delivery vector for gene therapy.

\section{CLINICAL TRIALS UTILIZING AAV VECTORS}

Due to rAAV's advantageous properties for in vivo gene delivery, approximately seventy clinical trials using rAAV as a gene delivery vector are currently open, have been completed, or are under review. Statistics surrounding these trials are summarized in Fig. (1). The clinical trials utilizing rAAV were reviewed several years ago [60]. The earliest clinical trials were conducted with rAAV2 vectors to treat cystic fibrosis and hemophilia B. Lately the number of diseases being tested for treatment utilizing AAV has greatly expanded and the newest clinical trials are utilizing serotypes other than AAV2. Here we discuss the history of clinical trials using rAAV for gene therapy and the advantages and problems with current AAV vectors elucidated by these trials.

\subsection{Early Trials with rAAV2}

a) Cystic Fibrosis-Thus far, nine clinical trials have been conducted using rAAV2 to treat cystic fibrosis, a monogenetic disease in which the cystic fibrosis transmembrane conductance regulator (CFTR) gene is mutated causing intestinal and airway difficulties (wiley.co.uk/genetherapy/clinical). All of these trials, of which seven are closed and two remain open, were conducted in the USA. Four phase I, three phase I/II, and three phase II trials have been performed in this area. These trials can be generally grouped into attempts to deliver the CFTR gene to the maxillary sinus and relieve chronic sinusitis and attempts to 
deliver the CFTR gene to the lung to allow thinning of the mucus and increased ease in breathing.

Several clinical trials have focused on transducing the epithelium of the maxillary sinus with the CFTR gene in an effort to relieve the persistent sinusitis associated with cystic fibrosis. The first of these trials was a phase I trial in which ten patients were treated with rAAV2CFTR in the sinuses. In this trial, no adverse effects were reported and dose-dependent transfer of the CFTR gene was observed, but there was no long-term effect of the treatment [112]. In a follow up phase II trial to assess the efficacy of treatment, the vector also caused no adverse effects; however, no efficacy of treatment was observed [113]. Further studies have not focused specifically on the sinuses, but instead focused on the lungs or on the airways in general.

The first trial to use rAAV as a gene therapy vector attempted to use rAAV2 to transduce the lungs with the CFTR gene in cystic fibrosis patients [114]. In this trial, no adverse effects were reported for rAAV2 but the treatment failed to demonstrate efficacy. In addition, a neutralizing antibody response developed to the AAV2 capsid, suggesting that readministration of vector might be problematic. In a separate trial, twelve patients were treated with no adverse effects. However, although the transgene was present throughout the lungs, no CFTR mRNA could be detected, suggesting a barrier to successful transduction [115]. Later in a larger trial of forty-two patients utilizing three doses of vector, an increase in interleukin-8 (IL-8) production and forced expiratory volume (FEV) suggested that this treatment protocol could lead to increased lung function for cystic fibrosis patients, although a neutralizing antibody response was developed [116]. However, a follow up study with approximately one hundred patients failed to demonstrate efficacy, even though the treatment was well tolerated and safe [117]. Overall, the early clinical trials utilizing rAAV2 to treat cystic fibrosis demonstrated the safety of rAAV mediated therapy, but suggested difficulty with the transduction of the epithelium with rAAV2.

b) Hemophilia B-To date, three phase I clinical trials have been conducted in the USA for the treatment of hemophilia B (F.IX deficiency) with rAAV2 mediated gene therapy. Although hemophilia is caused by the deficiency of a blood protein, the clinical trials conducted thus far have attempted to transduce either the muscle or the liver in order to facilitate the production of this protein. The first report on a hemophilia clinical trial with rAAV2 was a technical report on a trial with three patients conducted by Avigen, Inc [118]. This trial demonstrated that the treatment was safe and there was no evidence of germline transduction by the vector. In addition, there was a small response by two of the patients, even with the low dose of vector used. A further study, determined that, after hepatic artery injection of vector, the vector was transiently observed in the semen; however, this was not deemed a significant safety concern, as the vector was only present for a short period of time [119]. A phase I/II, dose escalation trial with seven patients, demonstrated that treatment was safe with little to no toxicity; however, although effective therapeutic levels of F.IX were developed with the highest dose of vector, these levels returned to baseline by eight weeks after treatment due to a cell-mediated immune response [120]. Overall, these trials demonstrate promising therapeutic value that is limited by immune responses, which were not predicted by animal model studies [121].

Other studies have examined the possibility of transducing the skeletal muscle through intramuscular (i.m.) injection of rAAV2 in order to produce F.IX. An early report with three patients determined that treatment was safe with no evidence for antibody production to F.IX or of transmission of the vector; however, this study also observed no evidence of successful transduction or of changes in the serum levels of F.IX [122]. A latter report confirmed through muscle biopsies that the transgene was expressed, although serum levels 
of F.IX only increased by $<1 \%$ to $2 \%$ [123]. This suggests that the treatment may have efficacy but that higher levels of vector introduced to a greater area of muscle is needed for successful treatment. In a follow up study, it was determined that this expression lasted for at least ten months, with a biopsy from one patient maintaining expression after almost four years [124]. This was the first evidence of successful, long-term expression of a transgene delivered by rAAV in humans. Overall, the trials with hemophilia and AAV2 suggest that clinical long-term transduction is possible, but greatly depends on the route of delivery and immune response.

\subsection{More Recent Trials with rAAV2}

Since the early trials with rAAV2, many clinical trials have been conducted with rAAV2 to treat different diseases. One disease that has received a great deal of attention is Leber Congenital Amerosis type 2, a disease caused by a deficiency in the RPE65 gene, which is involved in the retinoid cycle. This deficiency causes degenerating vision and eventually leads to blindness. The clinical trials conducted to treat this disease with rAAV mediated gene therapy are reviewed elsewhere in this issue.

a) CNS Delivery-Many rAAV gene therapy clinical trials have been conducted to treat diseases of the central nervous system (CNS) including Canavan disease, Parkinson's disease, Alzheimer's disease, amyotrophic lateral sclerosis, choroderaemia, and epilepsy. In all, twelve trials have been conducted for CNS disease of which two trials are closed while eight remain open (wiley.co.uk/genetherapy/clinical). Six of these trials are phase I, one is phase I/II, and five are phase II; the majority of the trials were conducted in the USA, although one was conducted in Sweden and one in Spain. The first use of viral vector mediated gene therapy for a neurodegenerative disorder was in a trial utilizing a rAAV2 vector to treat Canavan disease [125]. Canavan disease involves a defect in the aspartpoacylase gene leading to demyelination of neurons and spongiform degradation. In this trial, ten patients were treated with intracranial injections of the vector and no adverse effects or immune responses in the CNS were reported, although some systemic antibody responses were observed. This trial did not assess the efficacy of treatment, but the results were promising for the safety of rAAV delivery to the CNS.

Seven trials have been conducted to treat Parkinson's disease using rAAV2-mediated transfer of several different transgenes [126]. The first trial with published results introduced the glutamic acid decarboxylase (GAD) gene, responsible for synthesizing the inhibitory neurotransmitter GABA [127]. This phase I trial treated twelve patients with no adverse effects and observed significant improvements in function through one year after treatment. A phase II trial is now being conducted with the same vector to assess further the efficacy and safety of this treatment. In addition, one phase I trial was conducted and three phase II trials are being conducted with the CERE-120 vector, which is a rAAV2 vector carrying the neurturin gene, a neurotrophic factor. The results of the phase I trial have been published and demonstrate the safety of the treatment and some significant improvements in neurological function [128]. Results have not yet been published from the phase II trials. In addition, one phase I/II and one phase II trials have used the same vector to treat Alzheimer's disease. One further clinical trial is being conducted using a different neurotrophic factor, glial cell line-derived neurotrophic factor (GDNF), but results for this trial have not yet been reported.

Two further trials have been conducted to treat neurological disorders. The first treats late infantile neuronal ceroid lipofuscinosis, a lysosomal storage disease that leads to neurodegeneration, with rAAV2 carrying a functional copy of the defective gene. The second trial attempts to treat temporal lobe epilepsy with the introduction of a rAAV2 vector 
containing the neuropeptide $\mathrm{Y}$ gene to the hippocampus. Overall, the use of rAAV2 for gene delivery in the CNS holds great promise due to its safety and the long-term effects observed in this immunoprivileged site.

b) Other Trials-Many trials have also been conducted using rAAV2 to study other gene therapy applications. Two phase I clinical trials are being conducted in the USA to treat alpha-1 anti-trypsin (AAT) deficiency, which can lead to lung and liver damage due to decreased inactivation of trypsin. One of these trials utilized AAV2 and the results of this trial have been published [129]. This dose escalation trial, involving twelve patients, delivered the vector through i.m. injection and determined that the treatment was safe, although anti-vector antibodies were developed. The level of transgene expression was not determined. Furthermore, three phase I clinical trials have been conducted in the USA and Canada to treat inflammatory arthritis, such as rheumatoid arthritis (wiley.co.uk/ genetherapy/clinical). Two of these trials are closed and one is open. A published trial introduced a rAAV2 vector containing a TNF- $\alpha$ antagonist to the joint of fifteen patients through intra-articular injection [130]. Although the treatment was determined to be safe and well tolerated, the dose used was too low to determine if the treatment was efficacious.

A number of trials for other disease have also been initiated, although no results have yet been published. Sixteen trials have been conducted to evaluate the use of rAAV2 mediated gene therapy to treat cancer (wiley.co.uk/genetherapy/clinical). The majority of these trials are intended for metastatic hormone-refractive prostate cancer, although one phase I trial has been initiated to treat melanoma and another has been initiated to treat Epstein-Barr virus positive carcinoma. Seven of the prostate cancer trials, in the USA, UK, and Netherlands, are phase III trials. In addition to the many trials treating cancer, two trials are ongoing to evaluate the use of rAAV2 as a vector for gene therapy to treat heart failure and three trials have been conducted to use rAAV2 as a gene therapy vector to treat forms of muscular dystrophy including limb-girdle muscular dystrophy and Duchenne muscular dystrophy. Overall, these trials demonstrate the versatility of rAAV2 as a gene delivery vector; however, problems with pre-existing immunity, tropism, and loss of transgene expression have lead researchers to explore the use of other serotypes of AAV.

\subsection{Newer Trials with Other Serotypes of AAV}

Several trials have now been conducted that utilize the capsids of AAV serotypes other than AAV2 including AAV1, AAV6, AAV8, and AAVrh.10, as well as an engineered serotype, AAV2.5. All of these trials utilize a genome with AAV2 ITRs transencapsidated into the capsid of another serotype. The most trials have been conducted with rAAV2/1, which has greater tropism for muscle than AAV2. A phase I trial to treat AAT deficiency with a rAAV2/1 vector containing the AAT gene determined that i.m. injection of the vector was safe and was not related to any adverse effects [131]. Furthermore, although neutralizing antibody and cell-mediated immune responses were developed to the vector the expression of the AAT transgene was maintained for at least one year.

Trials have also been conducted for forms of muscular dystrophy using rAAV2/1 vectors. In a trial to treat limb-girdle muscular dystrophy, a rAAV2/1 vector was used to introduce the alpha-sarcoglycan gene through i.m. injection with a concurrent three-day course of methylpredisolone immunosuppression [132]. This treatment resulted in a capsid specific antibody response but very little cell-mediate immune response. In addition, increases in muscle fiber density, along with four to five fold increases in alpha-sarcoglycan levels, were observed at three months after treatment, demonstrating the promising nature of the treatment, despite the early time point. An additional phase I/II clinical trial is designed to treat Pompe disease, a glycogen storage disease leading to loss of muscle function, by 
delivery of a rAAV2/1 vector carrying the acid alpha-glycosidase gene to the diaphragm (wiley.co.uk/genetherapy/clinical). Results have not yet been published for this trial.

Furthermore, a phase I/II trial is also being conducted to treat lipoprotein lipase deficiency, a disease that leads to high serum triglyceride levels and pancreatitis. In this dose escalation trial, a rAAV2/1 vector carrying the lipoprotein lipase gene is delivered by i.m. injection. The highest dose of vector led to a $41 \%$ decrease in serum triglyceride levels; however, these levels returned to baseline by eighteen to thirty months after treatment [133].

Moreover, anti-capsid antibody and $\mathrm{T}$ cell immune responses were developed and, in at least one case, lead to cytotoxicity and transgene loss [134]. No anti-transgene immune responses were detected. One final rAAV2/1 trial introduces the vector containing the SERCA2a gene through intracoronary injection to treat heart failure. SERCA2a, or sarcoplasmic reticulum $\mathrm{Ca}^{2+}$ ATPase, is involved in calcium signaling regulation in cardiomyocytes and reduction in its function has been linked with heart failure [135]. Results of this trial have not yet been published.

Clinical trials have also been initiated with other serotypes of AAV, although no results have yet been published from these trials (wiley.co.uk/genetherapy/clinical). As AAV6 is much more efficient at transducing human airway epithelium cultures than other AAV serotypes [136], a phase I trial is currently examining its use to deliver the human placental alkaline phosphatase gene to the upper airway of cystic fibrosis patients in order to determine the efficacy of the rAAV2/6 vectors. In addition, one currently open trial and one trial with conditional approval are using self-complementary rAAV8 (scAAV2/8) to deliver the F.IX gene to the muscle to treat hemophilia. As AAV8 has strong expression in the muscle [137], enhanced by the self-complementary genome [108], this vector should allow for high levels of F.IX to be produced. Furthermore, AAV8 capsids tend to elicit high numbers of regulatory T cells, which may lead to longer-term transgene expression [138]. Another clinical trial, currently under review, will attempt to treat late infantile neuronal ceroid lipofuscinosis with CNS delivery of a simian serotype of AAV, AAVRrh.10. rAAVrh.10 demonstrated the highest expression levels, local spread, and clinical improvement of several AAV serotypes in pre-clinical mouse model studies [139]. One final clinical trial, for the treatment of Duchenne muscular dystrophy, utilizes a non-natural serotype of AAV known as AAV2.5, which incorporates capsid proteins with regions from more than one serotype of AAV. The recent trials using various serotypes of AAV demonstrate the versatility and adaptability of rAAV vectors.

\subsection{Clinical and Biological Issues with Current rAAV Vectors}

The many clinical trials utilizing rAAV vectors have demonstrated the safety and versatility of rAAV for gene delivery. However, although the recent trials with serotypes of AAV other than AAV2 have circumvented some issues with early clinical trials, some difficulties with current serotypes remain. Several trials have demonstrated that transgene expression is not maintained long-term in humans in nonimmunoprivileged sites [117, 123]. In addition, a few trials have suggested the possibility of vector dissemination at early time points after treatment [120]. Furthermore, it is possible that, if a transduced cell carried a wildtype AAV genome and was super-infected with a helper virus, the vector genome could be mobilized and disseminated. Transgene expression can also be inhibited by both pre-existing immunity to the AAV capsid [140] and by development of capsid specific immune responses to the vector $[117,123]$. The anti-capsid immune response also posses issues for re-administration of the vector. Moreover, a risk of insertional mutagenesis due to rAAV mediated gene therapy exists [111]. Some applications are also prevented by the limited packaging capacity of AAV. However, work with newer natural serotypes and with the design of non-natural capsids is leading to vectors that avoid many of these problems. The strategies being used to create these vectors are discussed below. 


\section{CAPSID DESIGN TO IMPROVE PERFORMANCE IN A CLINICAL SETTING}

A fundamental requirement of gene therapy is the ability to target specific tissues for therapeutic gene delivery and, equally importantly, to detarget those tissues that are unnecessary for correction of a given genetic disease. Production of an efficient targeted delivery system overcomes several limitations, including deleterious effects arising from the introduction of genetic material into the incorrect cell type, large therapeutic doses, and inefficient transduction of the tissue or cell type being targeted. To attempt to produce a targeted virus, extensive research has been performed on both the biology of individual natural serotypes as well as the construction of laboratory-derived serotypes that maximize gene delivery to intended tissue while avoiding sequestration in non-targeted tissue types. As increasing numbers of naturally occurring serotypes from different primate and other animal species have been discovered [141-146] (reviewed in [147]), the known diversity of AAV's tropism has broadened [137, 148-152]. This has important implications for the design of a targeted vector, as taking advantage of and enhancing the naturally ability of the virs has distinct advantages over de novo development of novel serotypes. The ability to transencapsidate AAV $[153,154]$ allows for a true comparison of capsid effects of targeting and transduction while avoiding any potential changes caused by the genome variation.

\subsection{Rational Design of the AAV Capsid based on Structural Analysis}

The emergence of several AAV serotypes' crystal and cryo-EM structures [68-71, 73-75, 155] as well as the co-crystal structure of AAV2 bound to its cognate heparin sul-fate proteoglycan receptor [156] has opened the door to rational design of the capsid based on its topological features. One of the most notable impacts these structures have had on rational design is the identity of regions of the AAV2 capsid that are involved in binding to heparin sulfate have been confirmed [157]. Indeed, in recent times researchers have become increasingly aware that this binding site on the capsid needs to be ablated in order to change AAV2 targeting [158-161]. However, the availability of the crystal structures has done more than confirm previous ideas: it has allowed researchers to begin devising specific plans for improving AAV2 targeting as well as transduction. To date, rational design of the capsid has been employed to improve targeting [162], gene expression [163, 164] and viral production [165]. Recent advances in rational design are discussed below.

The ability to use the AAV2/heparin sulfate co-crystal to design novel vectors is exemplified by a 2010 study by Asokan $e t$ al. in which the negatively charged patch comprising residues 585-590 of the AAV2 capsid - a surface loop known for its interaction with heparin sulfate - was swapped with residues 585-590 of AAV8, a vector known for its systemic transduction profile [137]. These mutations were made based on the alignment of the receptor footprint of the sero-types. It was hypothesized that the swap would not only ablate the binding of AAV2 to its natural receptor, thereby potentially detargeting the virus from the liver, but also confer some of the systemic dissemination properties of AAV8 to the virus. The new construct was termed AAV2i8 as it contains the AAV2 backbone with the inner loop of the threefold axis replaced with residues from AAV8. AAV2i8 exhibited a 40fold decrease in liver gene expression compared to AAV2 upon IV injection into C57BL/6 mice. Additionally, high expression levels were observed in all types of muscle cells, including cardiac, skeletal, facial, and diaphragm. Furthermore, low levels of expression were observed in brain, lung and spleen, illustrating that AAV2i8 has a tropism unique from either of its parental serotypes. While the receptor for this new construct is not known, it is clear is that there is sequestration in tissues other than the liver through heparin-sulfate independent uptake. One potential explanation for at least part of this new vector's widespread muscle transduction is that it exhibited markedly reduced blood clearancepersisting for well over 48 hours in circulation [162]. 
Creation of better vectors through rational design of the capsid has not been limited to improving tissue targeting abilities; in 2008 a series of papers were published illustrating that site-directed mutagenesis of the capsid can also be used to improve transduction efficiency [163, 164]. It had been previously established that EGFR-PTK phosphorylation of tyrosines in the viral capsid proteins negatively affects transduction levels, targeting the capsid for proteasomal degradation and thereby preventing nuclear localization of the vector $[166,167]$. Zhong et al. hypothesized that mutating each of the tyrosines that undergo phosphorylation to phospho-deficient phenylalanine would improve transduction by allowing the virus to escape degradation. The crystal structure of AAV2 was used to map solvent-exposed tyrosines on the capsid surface and 7 residues were chosen for mutation. It was determined that mutants $\mathrm{Y} 444 \mathrm{~F}$ and $\mathrm{Y} 730 \mathrm{~F}$ had the greatest impact on transduction efficiency, with up to a 29-fold gene expression increase observed in mouse hepatocytes after IV administration of these vectors to C57BL/6 mice. Furthermore, when the human Factor IX (hF.IX) gene was packaged in AAV2/Y730F vector, it was demonstrated that a 10-fold reduced therapeutic vector dose produced the same transduction levels as wild-type AAV2 [164]. Similar results were observed by Petrs-Silva et al., who used tyrosine to phenylalanine mutations at structurally equivalent positions on the capsids of AAV2, AAV8, and AAV9 to examine changes in transduction efficiency upon intravitreal delivery of vector to the retina. A 20 -fold increase in transduction of retinal cells was demonstrated for AAV2Y444F versus wild-type; additionally, many more cell types comprising the retinal ganglionic layer showed reporter gene expression that with wildtype virus. It should be noted that the tropism of these viruses had not been altered, but rather that transduction was enhanced with these mutations so that gene expression became measurable in additional retinal cell types. Fur thermore, none of these mutations conferred any negative impact to capsid stability or titer [163].

\subsection{Insertion of Targeting Ligands onto the AAV Capsid to Control Vector Tropism}

The insertion of targeting peptides onto the capsid surface in an effort to direct the virus to refractive cell types has been widely explored. To date, targeting peptides have enabled or enhanced transduction in muscle [168], lung [169, 170], circulatory vasculature [171], atherosclerotic lesions [172], hematopoietic progenitor cells [173, 174], vascular endothelial cells [175-177], pancreatic islet cells [178], various tumor lines [158, 160, 161, 179, 180], and leukemia cell lines [173, 174], among others. Two major areas of research have been utilized in these efforts: 1.) determination of capsid regions that will tolerate peptide insertions while maintaining an intact capsid and high-titer virus, and 2.) determination of targeting peptides to use in order to effectively direct the virus to a given cell type. When designing a virus to include targeting peptides for a cell-type specific receptor, a number of considerations must be accounted for. First, the peptide conformation and biological activity may be altered, attenuated, or completely ablated when placed in the context of the viral protein. Indeed, a given insertion site may not render a peptide solvent-accessible .

Secondly, peptides need to be selected not only for cell-type specific receptors but also for internalization into the cell so that AAV can deliver its genetic material. With the relatively limited knowledge of the receptorome of any given cell type this is not a trivial undertaking. Finally, the peptide insertion cannot deleteriously affect other aspects of the viral life cycle, including monomer association and capsid formation, genome packaging, intracellular trafficking, and viral uncoating to deliver DNA. A number of strategies that have been in employed to address these considerations are discussed below.

The original investigation into incorporating targeting peptides onto the virus focused on using phage-display identified or already known peptides that interact with specifically chosen receptors for insertion onto amenable regions of the capsid. Widespread insertion point analyses of the capsid using such peptides has been performed [79, 158-161, 179, 
181-184]. While some successes have been and continue to be apparent in pre-meditated choice of targeting peptides, a limitation of this approach is that it only optimizes receptor targeting and not other fundamental aspects of the viral life cycle. Additionally, the receptor being targeted may only exist at low levels on a given cell type. To overcome these limitations, approaches focusing on directed evolution of peptide ligands contained on the capsid surface for transduction of a given cell type have been developed. These approaches ensure that the virus can not only bind to a receptor, but also can complete internalization and genome delivery in the context of the inserted ligand.

A combinatorial, high-throughput approach is taken when performing directed evolution of targeting ligands in the context of the capsid [173-175, 179, 185-187]. Generally, a library is generated containing capsid-modified viral particles carrying random insertions of amino acids at a defined position. Common positions for these insertions are at residues 587 or 588 on the AAV2 capsid, as insertions in this region will disrupt the heparin-binding region of the capsid so that competition with heparin sulfate proteoglycan recognition is ablated. If using a position other than this for peptide insertion, site-directed mutagenesis of select residues within the capsid's heparin sulfate recognition region can improve targeting capacity [183]. The library of capsid mutants is then allowed to infect a given cell type in vitro and the viral progeny created in this cell type are harvested. This process is repeated iteratively until very few clones remain, in a strategy known as biopanning. The selective pressure provided by only choosing progeny that have been able to not only replicate within but also re-infect a given cell line ensures that the viral clones can accomplish each step in the viral life cycle successfully.

Recently, in vivo biopanning has been explored to enhance the selection process, as AAV particles do not need simply to be able to bind to a cell receptor, but need to achieve this interaction under circulation conditions. Additionally, they need to evade the host immune response, as well as overcome a variety of physical barriers while locating their target tissue type. In a combination in vitro and in vivo biopanning study, peptide-bearing viruses were subject to selection on breast and lung tumor tissue in vitro. These viruses were then subjected to a second round of selection in tumor bearing mice. While orders of magnitude increases in transduction of tumor tissue were observed in vivo, a surprising artifact of this study was the enhanced transduction of heart tissue in nearly all isolated vectors. This illustrates that subjecting vectors to in vivo selection is becoming fundamentally important both in the design of clinically relevant therapeutics, as well as in enhancing our understanding of AAV biology on a macroscopic scale [188].

\section{RANDOM MUTAGENESIS DESIGN OF ADENO-ASSOCIATED VIRAL VECTORS}

While ligands and peptide insertions provide a way to directly target specific cell receptors and might facilitate more efficient post-entry trafficking steps, these capsid additions have several limitations. First, the insertion is limited to locations on the capsid that will not negatively impact receptor-mediated entry or subsequent transduction. Therefore, rational design of peptide insertions requires pre-existing knowledge of capsid sites that are tolerant for insertions. Second, the specificity of many peptides or ligands depends on their conformation, so a simple insertion that does not achieve the correct three dimensional structure may be ineffective at its desired function. Third, a modified capsid may still be subject to neutralization by pre-existing anti-capsid antibodies. More recent strategies in capsid design, including engineering novel vectors that utilize the natural diversity of newly discovered serotypes, are being explored to achieve the same goals of non-natural capsid design: enhanced transduction, specific tropism, and immune evasion. These approaches include the creation of mosaic and chimeric capsids. 


\subsection{Mosaic Adeno-Associated Viral Vectors}

Mosaic capsid engineering allows for the creation of hybrid vectors that are heterogeneous at the protein level, i.e. the capsid proteins from more than one serotype of AAV are combined to compose a novel capsid particle Fig. (2A). In these production systems, plasmids encoding different viral proteins are added in a ratio that achieves the desired proportion of each viral protein within each capsid. In all of the reports using mosaic vectors, a certain ratio of viral proteins from two serotypes achieved additive effects in transduction. In the first report highlighting the utility of mosaic capsids, Hauck et al. engineered a vector consisting of AAV1 and AAV2 at a 50:50 ratio which achieved a several fold greater transduction in the liver and spleen as compared to the parent serotypes alone [189]. Furthermore, Rabinowitz et al. engineered mosaic viruses from combinations of AAV1-AAV5. Whereas AAV2 only binds to heparin and AAV5 only binds to mucin, the AAV3/5 (3:1) mosaic was able to bind to both mucin and heparin. Combining AAV1 with AAV2 and AAV1 with AAV3 allowed for enhanced transduction of some cell types over any parent serotype alone. Some changes in transduction were either abrupt or incremental depending on the composition of the mosaic capsid and the cell type [153].

Additionally, the use of mosaic viruses that contain part wild type viral proteins and part viral proteins with targeting ligand insertions restores the transduction capabilities that are often hampered when targeting ligands are on all of the monomers in the capsid. Efforts have been made to engineer a viral capsid with an ideal ratio of viral proteins with desired targeting properties along with transduction capabilities. For example, Gigout et al. created AAV2 mosaic capsids containing $25 \%$ capsid protein with an IgG binding fragment that, by adding an antibody, could be directed to cell targets while maintaining high levels of transduction. The success of these results is highlighted by the fact that a capsid composed of $100 \% \mathrm{IgG}$ containing viral particles yielded no transduction [190]. Moreover, the vasculature integrin targeting peptide RGD4C coupled with biotinylated viral proteins in a 90/10 ratio yielded vectors capable of efficient transduction of HeLa and HUVEC cells that could also be highly purified using avadin affinity chromatography [191].

The onset of mosaic vector engineering demonstrated for the first time ways to combine useful capsid components from more than one serotype to create an optimized vector with desired traits. However, because these vectors still consist of viral proteins from natural serotypes, they are likely to be subject to any preexisting immunity for the parent serotype.

\subsubsection{Directed Evolution Strategies for Adeno-Associated Vectors: In Vitro}

Selection-The natural course of AAV evolution has yielded serotypes with varying tissue tropism, antibody recognition, trafficking, replication, and gene transfer. Of course, naturally evolving viruses have been generated over a long period of time and with selective pressure from environmental factors. A rapidly developing strategy, known as directed evolution, exploits the natural course of evolution and serotype diversity through the creation of either chimeric or randomly mutated capsids. By applying recurrent rounds of selective pressure, an "evolved" chimera emerges exhibiting desirable traits rendering fitness for the given criteria. An example chimeric capsid is illustrated in Fig. (2B).

The first example of the directed evolution strategy was pioneered by Maheshri et al., where error-prone and staggered extension PCR was performed on AAV2 cap to produce a library of mutants. A selective pressure of a pre-incubation with rabbit anti-AAV2 serum followed by transduction and replication in $293 \mathrm{~T}$ cells was used. The resultant clones exhibited a diverse range of heparin binding, unlike AAV2 which has high affinity for heparin. The group determined that the variants could evade neutralizing antibodies, thought to be due to an alanine mutation on the C-terminus of VP3 observed in all of the variants. Furthermore, 
these variants could successfully deliver erythropoietin to mice even after opsonization with antiserum [192].

Li et al. and Koerber et al. expanded on this approach by using the DNA shuffling techniques developed by Stemmer [193, 194]. This approach involves fragmenting the cap genes of multiple AAV serotypes, reannealing the fragments in a primerless PCR reaction, and creating full length chimeric cap genes in a second PCR reaction. Chimeric viral libraries were generated comprised of the chimeric shell encapsidating the corresponding cap gene and AAV2 rep gene [195]. This group evolved a chimeric variant (AAV1829) that could transduce several melanoma cell lines and evade AAV2 neutralizing antibodies by shuffling the cap genes from AAV1-9 and selecting on Chinese hamster ovary cells. AAV1829 was also de-targeted from the liver when administered systemically and demonstrated less muscle transduction (after hind limb injection) than any of its parent serotypes [195]. Using a similar approach, Koerber et al. observed that chimeric capsids display a wide range of cell-type tropisms and sensitivity to neutralizing antibodies [196].

These initial studies demonstrated the utility of chimeras and created the platform for using high throughput selection approaches to evolve new AAVs with desired properties. For example, AAV-mediated therapy for cystic fibrosis has been hindered by limited gene transfer to airway epithelium. By shuffling AAV2 and AAV5 cap genes, Excoffon et al. were able to evolve a single chimera (AAV2.5T) from separate selections on different primary human airway epithelial cultures. This clone demonstrated significantly higher apical airway transduction compared to either parent which led to phenotypic correction of cystic fibrosis epithelia [197]. Two variants from an AAV1-9 library selected on human airway epithelial cultures (HAE-1 and HAE-2) could also transduce human cystic fibrosis airway epithelia and deliver the CFTR gene. Furthermore, this study demonstrated that the use of pharmacological agents could enhance transduction (see below: Future Directions) [198]. Using a combination of libraries produced by random mutagenesis, peptide display, and shuffling of AAV1-9, Koerber et al. evolved several variants with enhanced astrocyte tropism in vivo and one clone with enhanced Müller glia transduction over parent serotypes [199].

Shuffled viral libraries are rapidly expanding in diversity to include AAV serotypes not found in the human population in addition to well characterized serotypes. Grimm et al. created a shuffled library composed of avian, goat, and bovine AAV cap sequences in addition to AAV2, AAV4, AAV5, AAV8, and AAV9 cap sequences. This group evolved a virus (AAV-DJ) through selection on a liver hepatoma cell line with the additional pressure of pre-incubation in pooled human antisera. AAV-DJ demonstrated efficient transduction of several cell types over parent serotypes and was able to confer long-term hF.IX expression similar to AAV8 and AAV9 [170]. In addition, Rhesus macaque serotypes AAVrh.8 and AAVrh.10, along with AAV1, AAV2, AAV5, and AAV9 cap sequences were used to create a shuffled library that contained an evolved vector (AAV-U87R7-C5) with enhanced transduction capabilities for several glioma cell lines and human brain tumor stem cell neuro-spheres [200].

\subsubsection{Directed Evolution Strategies for Adeno-Associated Vectors: In Vivo}

Selection-Two groups have extended the in vitro efforts of directed evolution to a more physiologically relevant setting by using in vivo biopanning. The directed evolution approach in an in vivo setting removes any bias associated with cultured cells and produces variants with properties that more closely achieve therapeutic goals for whole tissues and organs. This process involves systemic administration of a chimeric viral library, resection of the target tissue, and PCR amplification of the sequestered vector genomes, which are then used in the next iterative cycle of selection. Using an AAV1-9 shuffled library, Yang et 
al. evolved a heart-tropic vector (AAVM41) with similar transduction levels as AAV9 but enhanced tropism (and detargeting from other tissue types) after systemic delivery. Furthermore, AAVM41 successfully mediated gene transfer of $\delta$-sarcoglycan to TO-2 hamsters, resulting in restoration of normal cardiac morphology and improved cardiac function [201]. Using a combined technique of compromising the blood brain barrier (BBB) with Kanic acid-induced seizure followed by the application of an AAV1-9 shuffled library, Gray et al. evolved a vector (clone83) that could efficiently transduce neurons and oligodendrocytes while being de-targeted from the liver and most other organs when administered systemically [202].

Currently, directed evolution is the fastest way to create novel AAV vectors that display enhanced tropism for specific cell types, are de-targeted from undesirable cell types, and achieve efficient transduction. Efforts have been made to enhance this approach, and developments will continue to yield improvements in vector design. Semi-random loop shuffling has been described, along with using combinatorial libraries to create widely diverse chimeras [197]. One caveat to the biopanning approaches is that results in cell lines and animal model may not be directly comparable to results in humans. Nevertheless, in vivo biopanning should continue to be explored, as directed evolution in an in vivo setting could yield AAV variants that are tumor-tropic or achieve efficient transduction in specific cell subsets. Efforts are ongoing in these areas and will likely lead to significant contributions in their respective fields.

\section{MODIFYING THE CAPSID WITH EXOGENOUS AGENTS}

While genetic manipulation of capsid proteins has shown great potential for the creation of targeted vectors, additional methods of vector design such as introducing exogenous agents to the viral capsid have been explored with some success. These approaches range from the use of bi-specific antibodies used to conjoin the virus to a receptor [203], facilitating celltype specific uptake, to biotinylation serving as a platform for conjugation targeting ligands [204-206]. Furthermore, coating the viral capsid in sheathing agents can serve not only to defy antibody neutralization but to act as derivitization platforms for targeting ligands [207, 208]. A few of the more recent exogenous agent targeting approaches are discussed below.

Carlisle et al. examined the ability to simultaneously retarget the virus and escape immune detection by coating the viral particle with reactive HPMA copolymers. Subjecting AAV5 and AAV8 to this coating efficiently shielded their natural receptor epitopes and attenuated natural receptor binding affinities as well as antibody recognition. Additionally, covalently linking specific targeting ligands to the polymer layer introduced receptor-specific targeting abilities. The charge profile of the AAV5 capsid interfered with the HPMA linking process and thus, while HPMA coating was accomplished on this serotype, it was at the expense of clinically relevant viral yields. AAV8, however, was highly tolerant to HPMA linkage. Coating of AAV8 in this manner led to significant detargeting of its natural cell targets. Copolymer pre-derivitized with murine EGF and linked to AAV8 resulted in significantly increased transduction of COS-7 cells over wild-type AAV8, demonstrating that this method can creating a novel tropism. Additionally, polymer coating improved AAV8 blood circulation time, with 3 -fold greater plasma levels versus wild-type virus 24 hours post i.v. injection into C57B16 mice [207].

In an effort to improve or alter in vivo lung tropism, Fein et al. used cationic lipid formulations to coat two chimeric AAV vectors known for their ability to transduce the alveolar epithelium [209]. Barriers implicit in the extracellular environment of the respiratory epithelium create a significant challenge for traditional gene delivery approaches. Dexamethasone-spermine (DS) and disubstituted spermine (D2S), two cationic sterol-based 
lipid formulations, were used to coat AAV2/9 and AAV2/6.2. An advantage of this strategy is that the lipid coating is formed through electro-static interaction with the capsid and does not neccessitate use of sophisticated covalent attachment chemistry. Lipid treatment caused the formation of 100-1000 virion clusters, which were delivered to cells. Transduction of A549 cells was increased 7-fold with AAV2/9 D2S treated particles relative to untreated virus. Following intranasal instillation of C57BL/6 mice, AAV2/6.2 treated with DS was determined to be the most efficacious combination, exhibiting a 4-fold increase in gene expression in the alveolar epithelium relative to non-lipid control. Additionally, it was demonstrated that when AAV2/9 was treated with DS and introduced to the nasal passage that the conducting airway was efficiently transduced. In the non-lipid AAV2/9 control, only alveolar epithelium exhibited transgene expression, illustrating a lipid-induced expansion of the vector's tropism. It is thought that the enhancements and differences in transduction observed in the lipid-treated virions are due to non-receptor mediated endocytosis of the lipid structure. If this is the case, then the formation of large clusters of viral particles upon lipid treatment may increase internalization of complexes containing multiple particles, increasing transgene copy number in the target cell population.

In a 2008 study, Bartlett et al. devised a strategy to covalently link either fluorophores or targeting ligands to the capsid without losing titer or causing other deleterious effects to the viral particle [206]. The goal of this study was to develop a platform that could be simultaneously used to attach a targeting ligand and/or a fluorphore to the capsid in order to gain information on how the ligand affects intracellular trafficking. While peptide insertions have proven to be a useful targeting tool, it is unclear what these genetic modifications of the capsid may alter other than simple receptor recognition. The development of a strategy that allows intracellular tracking of the virion to be followed in the presence of a targeting peptide can provide valuable illumination on potential viral life-cycle changes induced by the peptide.

To accomplish this, a biotin acceptor peptide (BAP) sequence was genetically inserted into the AAV1 capsid to serve as a recognition site for the E. coli enzyme BirA, which catalyzes the biotinylation of a specific lysine residue within the BAP consensus sequence. BirA will also accept isosteres of biotin in this reaction such as ketone 1, which is not present in naturally occurring proteins, lipids, and carbohydrates and thus allows for selective derivitization onto the capsid surface. Additionally, as the reaction is enzymatically performed, it occurs under physiological conditions so the capsid does not undergo harsh chemical processes. Covalent linkage of the ketone to the capsid allays any concerns that a fluorophore or targeting ligand can become detached during trafficking and confound the data [206].

To create an intracellular monitoring system of AAV, alexa fluor hydrazides were used to derivatize the ketones. This created a highly sensitive fluorescent labeling system that did not interfere with the particle's natural receptor utilization or intracellular trafficking. The system was then tested for the ability to accept conjugation of a synthetic cyclic-RGD peptide (c(RGDfC)) designed to target integrin receptors. The new vector demonstrated significantly enhanced transduction of cultured human endothelial cells, specific to the targeted integrin receptor. Furthermore, in a murine model of peritoneal ovarian cancer, i.v vector administration resulted in efficient gene transfer to the tumor-associated vasculature with no significant change in transduction of other key organs, such as the liver, spleen, and heart. Future efforts with this labeling technology will no doubt examine additional targeting ligands, as well as potential biophysical probes for monitoring changes in environmental $\mathrm{pH}$ or assaying PLA activity [206]. 


\section{USING TISSUE-SPECIFIC PROMOTERS FOR AN ADDITIONAL LEVEL OF TARGETING CONTROL}

An additional level of transcriptional targeting can be added to the virion through inclusion of tissue-specific promoters to drive expression of a given transgene. To develop a vector construct for treating a variety of genetic eye diseases effecting photoreceptors, Sun et al. used a promoter derived from the human rhodopsin kinase gene in order to drive the transgene expression. This promoter is known to be active in both rods and cones, but not in other regions of the eye, such as the retinal pigment epithelium (RPE). The promoter drove the expression of the transgene-AIPL1-at near endogenous levels in both types of cell [210]. While promoter-driven rod or cone-selective gene expression had been achieved previously [211-213], this represents the first successful example of targeting a transgene to both types of photoreceptor simultaneously. As expected, no transgene expression was observed in either the RPE or inner retinal neurons, confirming that the promoter was able to drive selective tissue expression of the virus [210].

Transcriptional targeting success has not been limited to the eye. The hTERT, the main component of human telom-erase, is selectively expressed in cancers [214]. As such, the tumor-specific hTERT promoter can be used to drive gene expression in cancers without achieving measurable expression activity in normal cells $[215,216]$. Using the hTERT promoter to drive the expression of cell lethal transgenes such as TRAIL and IFN- $\beta$ delivered by AAV vectors has demonstrated potent anti-tumor effects in mouse cancer models while sparing normal cells [217-219]. The promoter of the glucose transporter isoform 1 (GLUT1) is another cancer-specific transcription element that has been successfully used to drive selective transgene expression in tumors [220]. In fact, when combining the GLUT1 promoter with the herpes simplex virus thymidine kinase gene, treatment with gangciclovir achieved total tumor remission in a subcutaneous rodent model of hepatoma. These results indicate that combining a selective promoter with the correct capsid and transgene could create an attractive platform for the potential selective targeting of human cancers.

The use of tissue-specific promoters is proving to be an effective means of refining AAV targeting to desired tissue types. It is unlikely that the field will evolve to rely solely on promoter control of transgene expression as this strategy does not prevent viral sequestration in undesired cell types, which impacts how much virus is delivered to patient and necessitates unrealistically high therapeutic doses. The use of selective promoters does, however, allow refinement of targeting control on the genomic level, which can act in powerful synergism with targeting efforts on the protein level to improve therapeutic gene delivery designs [221].

\section{STRATEGIES TO AVOID THE IMMUNE RESPONSE}

\subsection{Immune Response to rAAV}

One of the biggest advantages of using AAV as a gene therapy vector over other viral options is that, traditionally, AAV is thought of as an essentially non-immunogenic virus, eliciting minimal innate and cellular immunity from the host. The major immune response to $\mathrm{AAV}$ is in the form of neutralizing antibody (NAb) formation to the capsid, which typically prevents receptor binding and cellular re-entry of AAV upon readministration In addition, the transgene product can also evoke an immune response, as the therapeutic protein is sometimes viewed as a "neoantigen" since the host may not recognize the protein as "self" [222-230]. 
The most prevalent AAV serotype in the human population is AAV2, with the first infection from this virus usually occurring in 30-80\% of the human population in early childhood [231]. This percentage is similar for AAV3 [232], while the seroprevalence of AAV6 is only about 30\% [233]. Less prevalent serotypes include AAV5, which has been determined to have infected between 10-20\% of the population [232-234], while AAV7 and AAV8 infection is only seen at a frequency of about $6 \%$ and elicit a minimal neutralizing antibody response [141]. Around $90 \%$ of humans harbor antibodies that react to one or more serotypes [63, 231, 232, 235-237]. Furthermore, memory T cell populations have been reported in around $60 \%$ of the population [238].

Recent work has mapped the origins of AAV immunity to the activation of the innate immune system, the host's first line of defense that shapes subsequent adaptive responses [239]. Zaiss et al. demonstrated that AAV2 interacts with complement component C3 and regulatory factor $\mathrm{H}$, to allow binding with $\mathrm{iC} 3 \mathrm{~b}$, which increases uptake into macrophages. Activation of the complement cascade occurred primarily through the classical pathway in vitro and through the alternative pathway in murine studies. In addition, C3 knockout mice challenged with AAV vectors specifically displayed deficient humoral activity compared to wild type mice [240]. In another study, Zaiss et al. identified many up regulated innate signaling molecules, along with recruitment of neutrophils and CD11b+ cells, upon I.V. administration of AAV2 in mice [241]. Zhu et al. demonstrated that AAV2, and to a lesser extent AAV1 and AAV9, activate plasmacytoid dendritic cells which though the TLR9/ MyD88 signaling pathway produce IFNa and IFN $\beta$. This signaling induced the activation of AAV-specific T cells which corresponded to a loss in transgene expression along with antibodies against the transgene and capsid [242].

Emerging data has identified antibody epitopes in humans and mice that elicit the humoral immune response $[243,244]$ and CD4+ and CD8+ T cell epitopes in humans and mice that elicit a cellular immune response [238, 245-247]. Human antibodies to AAV are primarily IgG1 and IgG2 but all IgG subclasses can be detected [248, 249]. Currently known AAV epitopes are illustrated in Fig. (2C). Furthermore, as AAV gene therapy advances to the clinical setting, it is coming to light that pre-clinical animal models may not be completely indicative of the immune response elicited in humans. NAb formation to rAAV has been documented in several clinical trials (see clinical trials section). Cell-mediated responses have also been reported. One of the first clinical trials sought to achieve long term therapeutic levels of human factor IX (hF.IX) through intrahepatic artery administration of AAV2 carrying the hF.IX transgene. Therapeutic hF.IX levels were transiently achieved in one subject in accordance with a rise and fall in liver transaminases [120]. These events were later determined to correspond to an expansion and contraction of CD8+ T cells specific for the AAV2 capsid along with the development of effector memory CD8+ T cells [238]. These results led the authors to propose that memory CD8+ T cells, formed after a previous wild type AAV infection with Adenovirus co-infection, expanded upon introduction of the recombinant vector and led to destruction of the transgene-expressing cells [250].

These results were not reflected in animal models and in fact conflict with some reports on the immune response to AAV2-mediated gene transfer in mice and non-human primates. Three separate groups demonstrated that capsid-specific CD8+ T cells were unable to elicit cytotoxic activity on transduced cells to eliminate transgene expression [251, 252]. Canine and non-human primate studies have also demonstrated disparities, with some reports of lack of detectable liver toxicity and no loss in F.IX expression [253, 254] and others observing inflammation, cell infiltrates, and loss of transgene expression resulting from intramuscular administration in canines regardless of serotype (AAV2 or AAV6) or transgene [252]. 
These discrepancies highlight the importance of population differences and prior AAV exposure when considering candidates for AAV-mediated gene therapy. Thus, when designing vectors for clinical purposes, several aspects should be considered. To escape preexisting immunity, AAV2-based vectors will need to be replaced with novel serotypes. By classic definition, a serotype is a species that cannot be neutralized by the antibodies of any other sero-type, nor can trigger antibody production that can neutralize any other serotype. Additionally, an immunologically covert vector would not induce a strong humoral response leading to NAb production, either from harboring immunodominant epitopes or an unintentional adjuvant. Therefore, re-administration with the same serotype could become a possibility. To achieve these desirable properties many groups have tried to identify new serotypes or modify the capsid with the goal of thwarting pre-existing memory or a robust immune response while at the same time maintaining infectivity and targeted tropism of the vector.

\subsection{Masking the Capsid Topology through PEGylation}

A method to modify the capsid without altering the actual coding sequence is covalent conjugation of poly-ethylene glycol (PEG). PEGylated Adenovirus has previously been observed to promote gene expression upon re-administration and evade neutralization by NAbs (46:23-26). The Adenovirus precedent inspired Le et al. and Lee et al. to experiment with PEGylation on the AAV capsid. Using succinimidyl propinoic acid, Lee et al. conjugated various sized PEG chains in a broad range of PEG:capsid ratios and demonstrated an inverse correlation between chain size and ratio with transduction and NAb escape [208]. Le et al. PEGylated AAV with three conjugation platforms and identified a neutralization-escaping variant-AAV2 modified with tresyl chloride PEG-that even achieved higher levels of transduction in vitro and in vivo than unmodified AAV2 [255]. PEGylation, along with other novel chemical modifications to the capsid, might prove to be a useful tool in combination with the following methods for immune response-escaping capsid design. However, changes to tropism and subcellular trafficking must be taken into consideration, as chemical modifications of surface residues would like lead to alterations in receptor binding and host-vector interactions.

\subsection{Transencapsidated Vectors: Novel Serotypes with Differential Immune Responses}

The first attempts at identifying new vectors for gene therapy was simply isolating new serotypes from humans and nonhuman primates that would escape pre-existing immunity or cross neutralization with other serotypes (for a review of vector development in AAV1-

AAV8 see [147]. These viruses have been evaluated as transencapsidated vectors, or capsids of the different serotypes packaging transgenes flanked by AAV2 ITRS. Most work thus far has investigated AAV2/2, AAV2/1, AAV2/6, and AAV2/5. Murine studies by Xiao et al. demonstrated that AAV2/1 and AAV2/2 do not cross react when administered in the muscle, which allows for readministration of the other vector after initial exposure to the first. Furthermore, in the liver, AAV2 only slightly inhibited readministration with AAV1 [256]. Halbert et al. demonstrated that AAV2/6 was less immunogenic than AAV2/2 and readministration with AAV2/6 or an administration of AAV2/6 following AAV2/2 achieved efficient transduction in mouse lung after intranasal delivery [257]. AAV2/2, AAV2/1, and AAV2/5 have demonstrated no cross-reactivity to each other [258-260], and AAV 2/5 can be administered through endotrachael delivery or intramuscularly following prior treatment with AAV2/2 or AAV2/1 [260]. Additionally, follow-up administration of AAV2/1 intramuscularly upon prior treatment with AAV2/2 or AAV2/5 improved gene transfer [259]. Furthermore, Gao et al. isolated AAV7 and AAV8 and demonstrated that they were immunologically distinct from any other serotype [141]. Similarly, Vandendriessche et al. determined that AAV2/9 andAAV2/8 were minimally immunogenic after systemic administration in mice [261]. Mayes et al. compared the immune profiles of AAV2/8 and 
non-human primate serotype AAVrh32.33 packaging LacZ reporter genes, which demonstrated no cross-reactivity and elicited distinct host responses. While AAV8 triggered a minimal CD4+ and CD8+ T cell response in mice, AAVrh32.33 evoked a robust cellular response, elevated IFN $\gamma$ production, and elicited almost 7 fold more LacZ-specific CD8+ T cells than AAV8, which correlated with a loss of transgene expression [262]. Novel serotypes may be abundant and demonstrate promise in certain therapeutic settings; however, different serotypes often use different cellular receptors for entry and thus differ in tropism and, therefore, may not be appropriate for the same applications. Furthermore, the use of alternative serotypes does not overcome the formation of immunological memory or neutralization by pre-existing immunity. Moreover, studies have determined that antibodies formed after the administration of one serotype can elicit neutralizing effects on a different serotype in humans $[238,245]$. Therefore, other methods are necessary to avoid immune responses.

\subsection{Identification and Disruption of Immunogenic Regions on the AAV Capsid}

In order to maintain the tropism for a given cell type but reduce inhibition by NAbs, efforts have been made to disrupt the known epitopes of the AAV capsid or other not yet known epitopes. Several immunogenic sites on the AAV2 capsid have been identified [120, 243, 245, 247], with other epitopes being exploited for common AAV2 capsid antibodies A1, A69, B1, and A20 [244]. Recently, through in vitro PBMC stimulation with a synthetic peptide library, Madsen et al. discovered 17 common immunodominant MHCI and MHCII capsid peptides, including 2 located on VP1 and 7 that shared homology to previously identified sequences. Some epitopes spanned multiple HLA haplotypes, indicating their prevalence in a capsid immune response [249]. Huttner et al. introduced laminin peptide insertions within surface loops on the AAV2 capsid. Insertions at residues 261, 534, 573, and 381 reduced the affinity of the A20 antibody for the capsid, while insertions at positions 534,573 , and 587 reduced the affinity of the C37-B antibody for the capsid. The insertion at position 587 also achieved neutralizing antibody evasion as human serum did not inhibit transduction of B16F10 cells [263]. Building on immunogenic residues previously identified [185, 192], Maersch et al. recently randomized AAV2 residues 449, 458, 459, 551, and 493 in a library essentially representing combinations of all 20 amino acids at all 5 positions. This library was incubated in neutralizing serum before selection on HEK 293 cells, which resulted in several "stealth" clones outperforming AAV2 in a transduction assay of HeLa cells in the presence of neutralizing serum. As immunological pressure was placed on the library, certain trends favoring some amino acid substitutions were noted. Specifically, small hydrophilic residues were favored overall and the incidence of an acidic residue at position 551 increased by 2 fold [264].

Oftentimes, intentions of achieving a certain desirable vector trait incidentally yields Nabresistant products. For example, Asokan et al. re-engineered the primary heparin sulfate binding domain of AAV2 in an attempt to design a vector with systemic tropism that was de-targeted from the liver. Consequently, this basic patch at the 3 fold spikes was replaced with residues in the same location from other serotypes. AAV2i8 (AAV2 with hexapeptide 585-QQNTAP-590 substituted at this site) not only ablated heparin sulfate binding but also allowed for persistent, systemic transduction, decreased liver tropism, and evasion from AAV2 NAbs and human sera [162]. This groups work compliments studies by Vandenberghe et al., who demonstrated that substituting the heparin sulfate binding motif RXXR motif of AAV2 into the same region on AAV8 resulted in enhanced CD8+ T cell activation [265]. The disruption of known receptor binding regions on AAV capsids to create neutralization-escaping vectors should be explored further, as this is a promising strategy to create a varity of vectors for given applications that will evade pre-existing immunity and allow re-administration for gene therapy applications. 


\subsection{Directed Evolution of Immunologically Covert Vectors}

While rational design to evade capsid neutralization may be feasible in some cases, there are many challenges to this approach. These include overcoming the prevalence of several epitopes, some of which are likely conformational, while maintaining infectivity and desired tropism. To meet these challenges in a rapid, unbiased setting, the directed evolution approach has been explored as a way to isolate novel, immune response-escaping vectors (see Non-rational design: Directed Evolution). In the first example of AAV directed evolution, Maheshri et al. created a library of mutants based on an AAV2 background in an attempt to recover AAV2-based variants that escaped neutralization. Four clones, all with a common T716A mutation, demonstrated a 3-fold improvement in NAb evasion. One clone (r2.15), isolated in a second round of selection, was 96-fold more infectious than AAV2 at the highest NAb titer tested. $\mathrm{r} 2.15$ administration in vivo delivered $23 \%$ more erythropoietin at the same NAb titer that reduced AAV2 delivery to basal levels [192].

Regardless of neutralization pressure, the directed evolution approach often yields immunologically distinct clones. In addition to isolating a variant specific to a $\mathrm{CHO}$ melanoma cell line, Li et al. demonstrated that chimeric-1829 remained completely unbound to the A20 antibody, was not cross-reactive with parent serotypes AAV1, AAV8, and AAV9, and displayed only mild cross-reactivity to AAV2 [195]. Similarly, Koerber et al. isolated several clones through directed evolution that were more resistant to pooled human IgGs than AAV1 or AAV2 without selection for NAb evasion [196]. Furthermore, in vivo selection of a myocardium tropic clone resulted in M41, which demonstrated over $20 \%$ more transduction activity in the presence of pooled human IgG serum than AAV2 does [201].

Capsid design approaches demonstrate promise in developing novel vectors that will avoid pre-existing immunity to naturally occurring serotypes. The capsid mutations that have lead to escape from pre-existing immunity are summarized in Fig. (2D). However, the feasibility of a second administration of these vectors remains variable, as the natural immune response will not spare these vectors. Furthermore, several studies have determined that, in addition to the AAV capsid, the transgene product can elicit an immune response, especially if the transgene contains alternative reading frames that encode for immunogenic proteins [266]. Therefore, capsid modifications cannot be the only strategy considered to improve vector efficacy.

\subsection{Delivery Strategies to Evade the Immune Response}

Extensive research has demonstrated that the route of delivery and destination of the AAV vector can have variable effects on the resultant immune response. Intramuscular, intraveneous, intraperitoneal, and subcutaneous administration seem to evoke the most robust immune response to the capsid and the transgene product [267-271]. Wang et al. reported that, upon i.m. administration of AAV2 encapsidating F.IX, expansion and contraction of IgG2 antibodies and prolonged IgG1 activity corresponded to a loss of F.IX transgene expression [270] and transgene-specific, dose-dependent CD4+ and CD8+ T cell proliferation corresponding to a loss of Ova expression [271]. In contrast, hepatic delivery has been observed to elicit a minimal immune response and even induce tolerance and anergy [269, 270, 272-277]. For example, in mice with CD4+ T cell receptors specific for an ova peptide, hepatic gene transfer of AAV2 with ova cDNA and an EF1 promoter led to decreased levels of IL-2 secretion and decreased levels of CD4+ T cells in in vitro ova stimulated splenocytes and inguinal lymph nodes as compared to hepatic gene transfer of AAV2 packaging GFP [273]. Furthermore, a general decrease of Ova-specific T cells coupled with an increase in CD4+CD25+FoxP3+ T cells, CD25+GITR+ T cells, and CD4+CD25+ T cells was observed [272]. Regardless of tolerance induction, hepatic gene 
transfer has been determined to elicit a $\mathrm{T}$ cell independent $\mathrm{B}$ cell response leading to $\mathrm{NAb}$ production in Rhesus macaques and mice [268].

Differences in immune activity are even detailed in immunoprivileged sites, which has lent insight into sub-organ delivery and re-administration timing. In a Phase I study for Canavan disease, rAAV2 encapsidating aspartoacylase delivered by intracranial administration. Then, sera was analyzed for Nabs and Nabs were identified in 7 out of 10 subjects with no NAbs for AAV2, 2 out of 10 subjects with low NAb activity, and 1 subject with a high NAb titer, which suggested recent exposure to wild type AAV [125]. In attempts to achieve gene transfer in the eye, Li et al. performed intravitreal and subretinal AAV delivery to mice. Administration to the vitreous a non-immunopriviledged site, resulted in a humoral response, which hindered successful transduction to the opposite eye. In contrast, subretinal administration was permissive to a second round of delivery to the opposite eye or an intravitreal administration [278]. Mastakov et al. performed re-administration studies in the rat brain and observed that, while only $3 \%$ of initial transduction levels was achieved with a second administration of AAV2 2 weeks after the initial delivery, $20 \%$ of initial transduction levels could be achieved if the second injection was administered 4 weeks after the initial delivery. Furthermore, complete restoration of transgene levels could be achieved if the second injection was delayed to 3 months [279]. In addition, Peden et al. demonstrated that repeat injections of AAV5 to the brain could be tolerated, and increasing the time interval between injections to 11 weeks resulted in no loss of transgene expression [280]. Moreover, Sabatino et al. demonstrated that the host age at the time of administration might be an important indicator of successful transgene expression. AAV2 encapsidating hF.IX delivered to adult mice resulted in hF.IX-specific antibodies and no long term hF.IX expression, where as in utero or neonatal treatment resulted in no detectable antibodies and long-term hF.IX expression[281].

\subsection{Concluding Immune Response Remarks}

As more information emerges from AAV clinical trials, it is becoming apparent that a more comprehensive investigation into the immune response elicited by AAV might be necessary to improve vector efficacy. Thus, the design of future vectors must include solutions to factors such as prior exposure in patient samples, prevalence of immunodominant epitopes on the capsid surface, and the route of vector delivery. Several reports have suggested that transient immuno-suppression reduces NAb proliferation and prolongs transgene expression [282-284]. However, immunosuppression may not be a favorable option for many patients. A recent study has demonstrated that the kinetics of transgene expression might play a role in the emergence of immunity [266]. Thus, self-complimentary vectors, which allow for more rapid transduction as they bypass second strand synthesis (the rate-limiting step in transgene expression) [108], might be an advantageous strategy. However, the limitations on packaging size implicated in self-complimentary vectors must be considered. Improvements in AAV safety to avoid humoral and cellular immunity will be ongoing as more information from clinical trials becomes available.

\section{CONCLUDING REMARKS}

As research progresses, the steps necessary to making adeno-associated virus a safe, effective gene delivery vehicle are becoming clear. Significant advances have been made with methods to create efficient, cell-specific targeting vectors in vitro, and these methods are now being applied to the in vivo setting to enhance therapeutic success. Our understanding of the immune system's relationship with AAV vectors has allowed for both the creation of vectors that are unable to be recognized and cleared from the body as well as delivery strategies to minimize the immune response. In the future, many new capsids will be developed that can simultaneously hide from the immune system and seek intended target 
tissues, but our greater understanding of vector biology will allow for the development of transgene design strategies synergistic with capsid design - such as clever design of the transgene in both enhancing target selectively through promoter choice as well as increasing genomic pay-load [285]. Furthermore, as we continue to evolve a comprehensive view of what is necessary to optimize AAV as a smart vector we can improve therapeutic safety, such as by preventing vector mobilization into the population [286]. In addition to vector design, as our understanding of AAV's intracellular biology advances we are also discovering new ways of enhancing gene expression, such as through the use of small molecules to inhibit proteasomal degradation of the particle [78]. In conclusion, though we have already seen great success with AAV-mediated gene therapy in both the laboratory and the clinic, the future of the clinical therapy holds even greater promise.

\section{Acknowledgments}

Thank you to Barry Kesner for help with the mosaic capsid image in Fig. (2A). This work was supported by the following NIH grants: 5-P01-GM059299, 2-P01-HL051818, 1R01AI072176, 1 U54 AR056953, 1R01EY019555, 1R01DK084033, 1R01 AI080726, and 5T32-AI007419.

\section{REFERENCES}

1. Kawabata K, Takakura Y, Hashida M. The fate of plasmid DNA after intravenous injection in mice: involvement of scavenger receptors in its hepatic uptake. Pharm Res. 1995; 12:825-30. [PubMed: 7667185]

2. Soutschek J, Akinc A, Bramlage B, et al. Therapeutic silencing of an endogenous gene by systemic administration of modified siRNAs. Nature. 2004; 432:173-8. [PubMed: 15538359]

3. Wooddell CI, Reppen T, Wolff JA, Herweijer H. Sustained liver-specific transgene expression from the albumin promoter in mice following hydrodynamic plasmid DNA delivery. J Gene Med. 2008; 10:551-63. [PubMed: 18330848]

4. Itaka K, Kataoka K. Recent development of nonviral gene delivery systems with virus-like structures and mechanisms. Eur J Pharm Biopharm. 2009; 71:475-83. [PubMed: 18955136]

5. Barteau B, Chevre R, Letrou-Bonneval E, Labas R, Lambert O, Pitard B. Physicochemical parameters of non-viral vectors that govern transfection efficiency. Curr Gene Ther. 2008; 8:31323. [PubMed: 18855629]

6. Montier T, Benvegnu T, Jaffres PA, Yaouanc JJ, Lehn P. Progress in cationic lipid-mediated gene transfection: a series of bio-inspired lipids as an example. Curr Gene Ther. 2008; 8:296-312. [PubMed: 18855628]

7. Itaka K, Harada A, Yamasaki Y, Nakamura K, Kawaguchi H, Kataoka K. In situ single cell observation by fluorescence resonance energy transfer reveals fast intra-cytoplasmic delivery and easy release of plasmid DNA complexed with linear polyethylenimine. J Gene Med. 2004; 6:76-84. [PubMed: 14716679]

8. Allen TM, Hansen C, Martin F, Redemann C, Yau-Young A. Liposomes containing synthetic lipid derivatives of poly(ethylene glycol) show prolonged circulation half-lives in vivo. Biochim Biophys Acta. 1991; 1066:29-36. [PubMed: 2065067]

9. Fisher KD, Ulbrich K, Subr V, et al. A versatile system for receptor-mediated gene delivery permits increased entry of DNA into target cells, enhanced delivery to the nucleus and elevated rates of transgene expression. Gene Ther. 2000; 7:1337-43. [PubMed: 10918506]

10. Dow SW, Fradkin LG, Liggitt DH, Willson AP, Heath TD, Potter TA. Lipid-DNA complexes induce potent activation of innate immune responses and antitumor activity when administered intravenously. J Immunol. 1999; 163:1552-61. [PubMed: 10415059]

11. Seow Y, Wood MJ. Biological Gene Delivery Vehicles: Beyond Viral Vectors. Mol Ther. 2009; 17:767-77. [PubMed: 19277019]

12. Nemunaitis J, Cunningham C, Senzer N, et al. Pilot trial of genetically modified, attenuated Salmonella expressing the E. coli cytosine deaminase gene in refractory cancer patients. Cancer Gene Ther. 2003; 10:737-44. [PubMed: 14502226] 
13. Schoen C, Kolb-Mäurer A, Geginat G, et al. Bacterial delivery of functional messenger RNA to mammalian cells. Cell Microbiol. 2005; 7:709-24. [PubMed: 15839900]

14. Moreno M, Kramer MG, Yim L, Chabalgoity JA. Salmonella as live trojan horse for vaccine development and cancer gene therapy. Curr Gene Ther. 2010; 10:56-76. [PubMed: 20156188]

15. Larsen MD, Griesenbach U, Goussard S, et al. Bactofection of lung epithelial cells in vitro and in vivo using a genetically modified Escherichia coli. Gene Ther. 2008; 15:434-42. [PubMed: 18317498]

16. Toso JF, Gill VJ, Hwu P, et al. Phase I study of the intravenous administration of attenuated Salmonella typhimurium to patients with metastatic melanoma. J Clin Oncol. 2002; 20:142-52. [PubMed: 11773163]

17. Byun HM, Suh D, Yoon H, et al. Erythrocyte ghost-mediated gene delivery for prolonged and blood-targeted expression. Gene Ther. 2004; 11:492-6. [PubMed: 14973541]

18. Doberstein SK, Wiegand G, Machesky LM, Pollard TD. Fluorescent erythrocyte ghosts as standards for quantitative flow cytometry. Cytometry. 1995; 20:14-8. [PubMed: 7600895]

19. Wang M, Tsou TH, Chen LS, et al. Inhibition of simian virus 40 large tumor antigen expression in human fetal glial cells by an antisense oligodeoxynucleotide delivered by the JC virus-like particle. Hum Gene Ther. 2004; 15:1077-90. [PubMed: 15610608]

20. Bundy BC, Franciszkowicz MJ, Swartz JR. Escherichia coli-based cell-free synthesis of virus-like particles. Biotechnol Bioeng. 2008; 100:28-37. [PubMed: 18023052]

21. Pattenden LK, Middelberg APJ, Niebert M, Lipin DI. Towards the preparative and large-scale precision manufacture of virus-like particles. Trends Biotechnol. 2005; 23:523-9. [PubMed: 16084615]

22. Shi W, Liu J, Huang Y, Qiao L. Papillomavirus pseudovirus: a novel vaccine to induce mucosal and systemic cytotoxic T-lymphocyte responses. J Virol. 2001; 75:10139-48. [PubMed: 11581382]

23. Hu Y-C. Baculoviral vectors for gene delivery: a review. Current Gene Therapy. 2008; 8:54-65. [PubMed: 18336250]

24. Kost TA, Condreay JP, Jarvis DL. Baculovirus as versatile vectors for protein expression in insect and mammalian cells. Nat Biotech. 2005; 23:567-75.

25. Strauss R, Huser A, Ni S, Tuve S, Kiviat N, Sow PS, Hofmann C, Lieber A. Baculovirus-based vaccination vectors allow for efficient induction of immune responses against Plasmodium falciparum circumsporozoite protein. Mol Ther. 2007; 15:193-202. [PubMed: 17164791]

26. Ho Y-C, Chung Y-C, Hwang S-M, Wang K-C, Hu Y-C. Transgene expression and differentiation of baculovirus-transduced human mesenchymal stem cells. J Gene Med. 2005; 7:860-8. [PubMed: 15712348]

27. Hervas-Stubbs S, Rueda P, Lopez L, Leclerc C. Insect baculoviruses strongly potentiate adaptive immune responses by inducing type I IFN. J Immunol. 2007; 178:2361-9. [PubMed: 17277142]

28. Hoare J, Waddington S, Thomas HC, Coutelle C, McGarvey MJ. Complement inhibition rescued mice allowing observation of transgene expression following intraportal delivery of baculovirus in mice. J Gene Med. 2005; 7:325-33. [PubMed: 15521052]

29. Kenoutis C, Efrose RC, Swevers L, et al. Baculovirus-mediated gene delivery into mammalian cells does not alter their transcriptional and differentiating potential but is accompanied by early viral gene expression. J Virol. 2006; 80:4135-46. [PubMed: 16571829]

30. Hu, Y-c. Baculovirus as a highly efficient expression vector in insect and mammalian cells. Acta Pharmacol Sin. 2005; 26:405-16. [PubMed: 15780188]

31. Pieroni L, Maione D, La Monica N. In vivo gene transfer in mouse skeletal muscle mediated by baculovirus vectors. Hum Gene Ther. 2001; 12:871-81. [PubMed: 11387053]

32. Jepson CD, March JB. Bacteriophage lambda is a highly stable DNA vaccine delivery vehicle. Vaccine. 2004; 22:2413-9. [PubMed: 15193403]

33. Shearer WT, Lugg DJ, Rosenblatt HM, et al. Antibody responses to bacteriophage X-174 in human subjects exposed to the Antarctic winter-over model of spaceflight. J Allergy Clin Immunol. 2001; 107:160-4. [PubMed: 11150006]

34. Greenstein D, Brent R. Introduction to vectors derived from filamentous phages. Curr Protoc Mol Biol. 2001 Chapter 1: Unit1 14. 
35. Piersanti S, Cherubini G, Martina Y, et al. Mammalian cell transduction and internalization properties of ? phages displaying the full-length adenoviral penton base or its central domain. $\mathrm{J}$ Mol Med. 2004; 82:467-76. [PubMed: 15150649]

36. Molenaar TJM, Michon I, de Haas SAM, van Berkel TJC, Kuiper J, Biessen EAL. Uptake and processing of modified bacteriophage $\mathrm{m} 13$ in mice: implications for phage display. Virology. 2002; 293:182-91. [PubMed: 11853411]

37. Cripe TP, Wang P-Y, Marcato P, Mahller YY, Lee PWK. Targeting cancer-initiating cells with oncolytic viruses. Mol Ther. 2009; 17:1677-82. [PubMed: 19672244]

38. Collins SA, Guinn BA, Harrison PT, Scallan MF, O'Sullivan GC, Tangney M. Viral vectors in cancer immunotherapy: which vector for which strategy? Curr Gene Ther. 2008; 8:66-78. [PubMed: 18393828]

39. Fernandez M, Porosnicu M, Markovic D, Barber GN. Genetically engineered vesicular stomatitis virus in gene therapy: application for treatment of malignant disease. J Virol. 2002; 76:895-904. [PubMed: 11752178]

40. Otsuki A, Patel A, Kasai K, et al. Histone deacetylase inhibitors augment antitumor efficacy of herpes-based oncolytic Viruses. Mol Ther. 2008; 16:1546-55. [PubMed: 18648350]

41. Eriksson M, Guse K, Bauerschmitz G, et al. Oncolytic adenoviruses kill breast cancer initiating CD44+CD24-/low cells. Mol Ther. 2007; 15:2088-93. [PubMed: 17848962]

42. Jiang H, Gomez-Manzano C, Lang FF, Alemany R, Fueyo J. Oncolytic adenovirus: preclinical and clinical studies in patients with human malignant gliomas. Curr Gene Ther. 2009; 9:422-7. [PubMed: 19860656]

43. Marcato P, Dean CA, Giacomantonio CA, Lee PWK. Oncolytic reovirus effectively targets breast cancer stem cells. Mol Ther. 2009; 17:972-9. [PubMed: 19293772]

44. Galanis E, Hartmann LC, Cliby WA, et al. Phase I trial of intraperitoneal administration of an oncolytic measles virus strain engineered to express carcinoembryonic antigen for recurrent ovarian cancer. Cancer Res. 70:875-82. [PubMed: 20103634]

45. Blechacz B, Russell SJ. Measles virus as an oncolytic vector platform. Curr Gene Ther. 2008; 8:162-75. [PubMed: 18537591]

46. Garber K. China approves World's first oncolytic virus therapy for cancer treatment. J Natl Cancer Inst. 2006; 98:298-300. [PubMed: 16507823]

47. Gollamudi R, Ghalib M, Desai K, et al. Intravenous administration of Reolysin ${ }^{\circledR}$, a live replication competent RNA virus is safe in patients with advanced solid tumors. Investigat New Drugs. 2010; 28(5):641-9.

48. Douglas J. Adenoviral vectors for gene therapy. Mol Biotechnol. 2007; 36:71-80. [PubMed: 17827541]

49. Schambach A, Baum C. Clinical application of lentiviral vectors --concepts and practice. Curr Gene Ther. 2008; 8:474-82. [PubMed: 19075630]

50. Naldini L, Blomer U, Gallay P, et al. In Vivo Gene delivery and stable transduction of nondividing cells by a lentiviral vector. Science. 1996; 272:263-7. [PubMed: 8602510]

51. Funke S, Maisner A, Muhlebach MD, et al. Targeted cell entry of lentiviral vectors. Mol Ther. 2008; 16:1427-36. [PubMed: 18578012]

52. Mitchell RS, Beitzel BF, Schroder ARW, et al. Retroviral DNA integration: ASLV, HIV, and MLV show distinct target site preferences. PLoS Biol. 2004; 2:e234. [PubMed: 15314653]

53. Lewinski MK, Yamashita M, Emerman M, et al. Retroviral DNA integration: viral and cellular determinants of target-site selection. PLoS Pathog. 2006; 2:e60. [PubMed: 16789841]

54. Ellis J. Silencing and variegation of gammaretrovirus and lentivirus vectors. Hum Gene Ther. 2005; 16:1241-6. [PubMed: 16259557]

55. Towers $\mathrm{G}$. The control of viral infection by tripartite motif proteins and cyclophilin A. Retrovirology. 2007; 4:40. [PubMed: 17565686]

56. Engelman A, Cherepanov P. The lentiviral integrase binding protein LEDGF/p75 and HIV-1 replication. PLoS Pathog. 2008; 4:e1000046. [PubMed: 18369482] 
57. Cartier N, Hacein-Bey-Abina S, Bartholomae CC, et al. Hematopoietic stem cell gene therapy with a lentiviral vector in $\mathrm{x}$-linked adrenoleukodystrophy. Science. 2009; 326:818-23. [PubMed: 19892975]

58. Bayer M, Kantor B, Cockrell A, et al. A large U3 deletion causes increased in vivo expression from a nonintegrating lentiviral vector. Mol Ther. 2008; 16:1968-76. [PubMed: 18797449]

59. Sarkis C, Philippe S, Mallet J, Serguera C. Non-integrating lentiviral vectors. Curr Gene Ther. 2008; 8:430-7. [PubMed: 19075626]

60. Mueller C, Flotte TR. Clinical gene therapy using recombinant adeno-associated virus vectors. Gene Ther. 2008; 15:858-63. [PubMed: 18418415]

61. Berns KI, Pinkerton TC, Thomas GF, Hoggan MD. Detection of adeno-associated virus (AAV)specific nucleotide sequences in DNA isolated from latently infected Detroit 6 cells. Virology. 1975; 68:556-60. [PubMed: 1198930]

62. Rabinowitz JE, Rolling F, Li C, et al. Cross-packaging of a single adeno-associated virus (AAV) type 2 vector genome into multiple AAV serotypes enables transduction with broad specificity. $\mathrm{J}$ Virol. 2002; 76:791-801. [PubMed: 11752169]

63. Atchison RW, Casto BC, Hammon WM. Adenovirus-Associated defective virus particles. Science. 1965; 149:754-6. [PubMed: 14325163]

64. Gao G, Vandenberghe LH, Alvira MR, et al. Clades of adeno-associated viruses are widely disseminated in human tissues. J Virol. 2004; 78:6381-8. [PubMed: 15163731]

65. McCarty DM, Ryan JH, Zolotukhin S, Zhou X, Muzyczka N. Interaction of the adeno-associated virus Rep protein with a sequence within the A palindrome of the viral terminal repeat. J Virol. 1994; 68:4998-5006. [PubMed: 8035499]

66. Kyostio SR, Owens RA, Weitzman MD, Antoni BA, Chejanovsky N, Carter BJ. Analysis of adeno-associated virus (AAV) wild-type and mutant Rep proteins for their abilities to negatively regulate AAV p5 and p19 mRNA levels. J Virol. 1994; 68:2947-57. [PubMed: 8151765]

67. King JA, Dubielzig R, Grimm D, Kleinschmidt JA. DNA helicase-mediated packaging of adenoassociated virus type 2 genomes into preformed capsids. EMBO J. 2001; 20:3282-91. [PubMed: 11406604]

68. Miller EB, Gurda-Whitaker B, Govindasamy L, et al. Production, purification and preliminary Xray crystallographic studies of adeno-associated virus serotype 1. Acta Crystallogr Sect F Struc Biol Cryst Commun. 2006; 62:1271-4.

69. Kronenberg S, Kleinschmidt JA, Bottcher B. Electron cryo-microscopy and image reconstruction of adeno-associated virus type 2 empty capsids. EMBO Rep. 2001; 2:997-1002. [PubMed: 11713191]

70. Kaludov N, Padron E, Govindasamy L, McKenna R, Chiorini JA, Agbandje-McKenna M. Production, purification and preliminary X-ray crystallographic studies of adeno-associated virus serotype 4. Virology. 2003; 306:1-6. [PubMed: 12620791]

71. Walters RW, Agbandje-McKenna M, Bowman VD, et al. Structure of adeno-associated virus serotype 5. J Virol. 2004; 78:3361-71. [PubMed: 15016858]

72. Xie Q, Ongley HM, Hare J, Chapman MS. Crystallization and preliminary X-ray structural studies of adeno-associated virus sero-type 6. Acta Crystallogr Sect F Struct Biol Cryst Commun. 2008; 64:1074-8.

73. Quesada O, Gurda B, Govindasamy L, et al. Agbandje-McKenna M. Production, purification and preliminary X-ray crystallographic studies of adeno-associated virus serotype 7. Acta Crystallogr Sect F Struct Biol Cryst Commun. 2007; 63:1073-6.

74. Nam H-J, Lane MD, Padron E, et al. Structure of adeno-associated virus serotype 8, a gene therapy vector. J Virol. 2007; 81:12260-71. [PubMed: 17728238]

75. Mitchell M, Nam HJ, Carter A, et al. Production, purification and preliminary X-ray crystallographic studies of adeno-associated virus serotype 9. Acta Crystallogr Sect F Struct Biol Cryst Commun. 2009; 65:715-8.

76. Wistuba A, Kern A, Weger S, Grimm D, Kleinschmidt JA. Subcellular compartmentalization of adeno-associated virus type 2 assembly. J Virol. 1997; 71:1341-52. [PubMed: 8995658]

77. Bartlett JS, Wilcher R, Samulski RJ. Infectious entry pathway of adeno-associated virus and adeno-associated virus vectors. J Virol. 2000; 74:2777-85. [PubMed: 10684294] 
78. Johnson JS, Samulski RJ. Enhancement of adeno-associated virus infection by mobilizing capsids into and out of the nucleolus. J Virol. 2009; 83:2632-44. [PubMed: 19109385]

79. Grieger JC, Johnson JS, Gurda-Whitaker B, Agbandje-McKenna M, Samulski RJ. SurfaceExposed adeno-associated virus Vp1-NLS capsid fusion protein rescues infectivity of noninfectious wild-type $\mathrm{Vp} 2 / \mathrm{Vp} 3$ and $\mathrm{Vp} 3$-only capsids but not that of fivefold pore mutant virions. J Virol. 2007; 81:7833-43. [PubMed: 17507473]

80. Rabinowitz JE, Samulski RJ. Building a better vector: the manipulation of AAV virions. Virology. 2000; 278:301-8. [PubMed: 11118354]

81. Ferrari FK, Samulski T, Shenk T, Samulski RJ. Second-strand synthesis is a rate-limiting step for efficient transduction by recombinant adeno-associated virus vectors. J Virol. 1996; 70:3227-34. [PubMed: 8627803]

82. Cheung AK, Hoggan MD, Hauswirth WW, Berns KI. Integration of the adeno-associated virus genome into cellular DNA in latently infected human Detroit 6 cells. J Virol. 1980; 33:739-48. [PubMed: 6251245]

83. Kotin RM, Siniscalco M, Samulski RJ, et al. Site-specific integration by adeno-associated virus. Proc Nat Acad Sci USA. 1990; 87:2211-5. [PubMed: 2156265]

84. Samulski RJ, Zhu X, Xiao X, et al. Targeted integration of adeno-associated virus (AAV) into human chromosome 19. EMBO J. 1991; 10:3941-50. [PubMed: 1657596]

85. Georg-Fries B, Biederlack S, Wolf J, Zur Hausen H. Analysis of proteins, helper dependence, and seroepidemiology of a new human parvovirus. Virology. 1984; 134:64-71. [PubMed: 6200995]

86. Schlehofer JR, Ehrbar M, Hausen HZ. Vaccinia virus, herpes simplex virus, and carcinogens induce DNA amplification in a human cell line and support replication of a helpervirus dependent parvo-virus. Virology. 1986; 152:110-7. [PubMed: 3012864]

87. Walz C, Deprez A, Dupressoir T, Durst M, Rabreau M, Schlehofer JR. Interaction of human papillomavirus type 16 and adeno-associated virus type 2 co-infecting human cervical epithelium. J Gen Virol. 1997; 78:1441-52. [PubMed: 9191942]

88. Ogston P, Raj K, Beard P. Productive replication of adeno-associated virus can occur in human papillomavirus type 16 (HPV-16) episome-containing keratinocytes and is augmented by the HPV-16 E2 Protein. J Virol. 2000; 74:3494-504. [PubMed: 10729123]

89. Yakobson B, Koch T, Winocour E. Replication of adeno-associated virus in synchronized cells without the addition of a helper virus. J Virol. 1987; 61:972-81. [PubMed: 3029431]

90. Yakobson B, Hrynko TA, Peak MJ, Winocour E. Replication of adeno-associated virus in cells irradiated with UV light at $254 \mathrm{~nm}$. J Virol. 1989; 63:1023-30. [PubMed: 2536816]

91. Xiao W, Warrington KH Jr. Hearing P, Hughes J, Muzyczka N. Adenovirus-Facilitated nuclear translocation of adeno-associated virus type 2. J Virol. 2002; 76:11505-17. [PubMed: 12388712]

92. Fisher KJ, Gao GP, Weitzman MD, DeMatteo R, Burda JF, Wilson JM. Transduction with recombinant adeno-associated virus for gene therapy is limited by leading-strand synthesis. $\mathrm{J}$ Virol. 1996; 70:520-32. [PubMed: 8523565]

93. Duan D, Sharma P, Dudus L, et al. Formation of adeno-associated virus circular genomes is differentially regulated by adenovirus E4 ORF6 and E2a gene expression. J Virol. 1999; 73:161-9. [PubMed: 9847318]

94. Duan D, Sharma P, Yang J, et al. Circular Intermediates of recombinant adeno-associated virus have defined structural characteristics responsible for long-term episomal persistence in muscle tissue. J Virol. 1998; 72:8568-77. [PubMed: 9765395]

95. Chang LS, Shenk T. The adenovirus DNA-binding protein stimulates the rate of transcription directed by adenovirus and adeno-associated virus promoters. J Virol. 1990; 64:2103-9. [PubMed: 2157873]

96. Chang LS, Shi Y, Shenk T. Adeno-associated virus P5 promoter contains an adenovirus E1Ainducible element and a binding site for the major late transcription factor. J Virol. 1989; 63:347988. [PubMed: 2545917]

97. Shi Y, Seto E, Chang LS, Shenk T. Transcriptional repression by YY1, a human GLI-Kruppelrelated protein, and relief of repression by adenovirus E1A protein. Cell. 1991; 67:377-88. [PubMed: 1655281] 
98. Mouw MB, Pintel DJ. Adeno-Associated virus RNAs appear in a temporal order and their splicing is stimulated during coinfection with adenovirus. J Virol. 2000; 74:9878-88. [PubMed: 11024114]

99. Samulski RJ, Shenk T. Adenovirus E1B 55-Mr polypeptide facilitates timely cytoplasmic accumulation of adeno-associated virus mRNAs. J Virol. 1988; 62:206-10. [PubMed: 2824848]

100. Janik JE, Huston MM, Cho K, Rose JA. Efficient synthesis of adeno-associated virus structural proteins requires both adenovirus DNA binding protein and VA I RNA. Virology. 1989; 168:320-9. [PubMed: 2536986]

101. Carter BJ, Marcus-Sekura CJ, Laughlin CA, Ketner G. Properties of an adenovirus type 2 mutant, $\mathrm{Ad} 2 \mathrm{~d} / 807$, having a deletion near the right-hand genome terminus: Failure to help AAV replication. Virology. 1983; 126:505-16. [PubMed: 6305001]

102. Huang MM, Hearing P. Adenovirus early region 4 encodes two gene products with redundant effects in lytic infection. J Virol. 1989; 63:2605-15. [PubMed: 2724411]

103. Ward P, Dean FB, O'Donnell ME, Berns KI. Role of the Adenovirus DNA-binding protein in in vitro adeno-associated virus DNA replication. J Virol. 1998; 72:420-7. [PubMed: 9420241]

104. Geoffroy M-C, Salvetti A. Helper functions required for wild type and recombinant adenoassociated virus growth. Curr Gene Ther. 2005; 5:265-71. [PubMed: 15975004]

105. Xiao X, Xiao W, Li J, Samulski RJ. A novel 165-base-pair terminal repeat sequence is the sole cis requirement for the adeno-associated virus life cycle. J Virol. 1997; 71:941-8. [PubMed: 8995611]

106. Grieger JC, Choi VW, Samulski RJ. Production and characterization of adeno-associated viral vectors. Nat Protoc. 2006; 1:1412-28. [PubMed: 17406430]

107. McCarty DM, Monahan PE, Samulski RJ. Self-complementary recombinant adeno-associated virus (scAAV) vectors promote efficient transduction independently of DNA synthesis. Gene Ther. 2001; 8:1248-54. [PubMed: 11509958]

108. McCarty DM, Fu H, Monahan PE, Toulson CE, Naik P, Samulski RJ. Adeno-associated virus terminal repeat (TR) mutant generates self-complementary vectors to overcome the rate-limiting step to transduction in vivo. Gene Ther. 2003; 10:2112-8. [PubMed: 14625565]

109. Nakai H, Yant SR, Storm TA, Fuess S, Meuse L, Kay MA. Extrachromosomal recombinant adeno-associated virus vector genomes are primarily responsible for stable liver transduction in vivo. J Virol. 2001; 75:6969-76. [PubMed: 11435577]

110. Miao CH, Snyder RO, Schowalter DB, et al. The kinetics of rAAV integration in the liver. Nat Genet. 1998; 19:13-5. [PubMed: 9590280]

111. Miller DG, Trobridge GD, Petek LM, Jacobs MA, Kaul R, Russell DW. Large-Scale analysis of adeno-associated virus vector integration sites in normal human cells. J Virol. 2005; 79:1143442. [PubMed: 16103194]

112. Wagner JA, Messner AH, Moran ML, et al. Safety and biological efficacy of an adeno-associated virus vector-cystic fibrosis trans-membrane regulator (AAV-CFTR) in the cystic fibrosis maxillary sinus. Laryngoscope. 1999; 109:266-74. [PubMed: 10890777]

113. Wagner JA, Nepomuceno IB, Messner AH, et al. A phase II, double-blind, randomized, placebocontrolled clinical trial of tgAAVCF using maxillary sinus delivery in patients with cystic fibrosis with antrostomies. Hum Gene Ther. 2002; 13:1349-59. [PubMed: 12162817]

114. Flotte TR, Zeitlin PL, Reynolds TC, et al. Phase I trial of intranasal and endobronchial administration of a recombinant adeno-associated virus serotype 2 (rAAV2)-CFTR vector in adult cystic fibrosis patients: a two-part clinical study. Hum Gene Ther. 2003; 14:1079-88. [PubMed: 12885347]

115. Aitken ML, Moss RB, Waltz DA, et al. A phase I study of aerosolized administration of tgAAVCF to cystic fibrosis subjects with mild lung disease. Hum Gene Ther. 2001; 12:1907-16. [PubMed: 11589832]

116. Moss RB, Rodman D, Spencer LT, et al. Repeated adeno-associated virus serotype 2 aerosolmediated cystic fibrosis trans-membrane regulator gene transfer to the lungs of patients with cystic fibrosis: a multicenter, double-blind, placebo-controlled trial. Chest. 2004; 125:509-21. [PubMed: 14769732] 
117. Moss RB, Milla C, Colombo J, et al. Repeated aerosolized AAV-CFTR for treatment of cystic fibrosis: a randomized placebo-controlled phase 2B trial. Hum Gene Ther. 2007; 18:726-32. [PubMed: 17685853]

118. Fabb SA, Dickson JG. Technology evaluation: AAV factor IX gene therapy, Avigen Inc. Curr Opin Mol Ther. 2000; 2:601-6. [PubMed: 11249763]

119. Schuettrumpf J, Liu JH, Couto LB, et al. Inadvertent germline transmission of AAV2 vector: findings in a rabbit model correlate with those in a human clinical trial. Mol Ther. 2006; 13:1064-73. [PubMed: 16631412]

120. Manno CS, Pierce GF, Arruda VR, et al. Successful transduction of liver in hemophilia by AAVFactor IX and limitations imposed by the host immune response. Nat Med. 2006; 12:342-7. [PubMed: 16474400]

121. Snyder RO, Miao CH, Patijn GA, et al. Persistent and therapeutic concentrations of human factor IX in mice after hepatic gene transfer of recombinant AAV vectors. Nat Genet. 1997; 16:270-6. [PubMed: 9207793]

122. Kay MA, Manno CS, Ragni MV, et al. Evidence for gene transfer and expression of factor IX in haemophilia B patients treated with an AAV vector. Nat Genet. 2000; 24:257-61. [PubMed: 10700178]

123. Manno CS, Chew AJ, Hutchison S, et al. AAV-mediated factor IX gene transfer to skeletal muscle in patients with severe hemophilia B. Blood. 2003; 101:2963-72. [PubMed: 12515715]

124. Jiang H, Pierce GF, Ozelo MC, et al. Evidence of multiyear factor IX expression by AAVmediated gene transfer to skeletal muscle in an individual with severe hemophilia B. Mol Ther. 2006; 14:452-5. [PubMed: 16822719]

125. McPhee SW, Janson CG, Li C, et al. Immune responses to AAV in a phase I study for Canavan disease. J Gene Med. 2006; 8:577-88. [PubMed: 16532510]

126. Carlsson T, Bjorklund T, Kirik D. Restoration of the striatal dopa-mine synthesis for Parkinson's disease: viral vector-mediated enzyme replacement strategy. Curr Gene Ther. 2007; 7:109-20. [PubMed: 17430130]

127. Kaplitt MG, Feigin A, Tang C, et al. Safety and tolerability of gene therapy with an adenoassociated virus (AAV) borne GAD gene for Parkinson's disease: an open label, phase I trial. Lancet. 2007; 369:2097-105. [PubMed: 17586305]

128. Marks WJ Jr. Ostrem JL, Verhagen L, et al. Safety and tolerability of intraputaminal delivery of CERE-120 (adeno-associated virus serotype 2-neurturin) to patients with idiopathic Parkinson's disease: an open-label, phase I trial. Lancet Neurol. 2008; 7:400-8. [PubMed: 18387850]

129. Brantly ML, Spencer LT, Humphries M, et al. Phase I trial of intramuscular injection of a recombinant adeno-associated virus sero-type 2 alphal-antitrypsin (AAT) vector in AATdeficient adults. Hum Gene Ther. 2006; 17:1177-86. [PubMed: 17115945]

130. Mease PJ, Hobbs K, Chalmers A, et al. Local delivery of a recombinant adenoassociated vector containing a tumour necrosis factor alpha antagonist gene in inflammatory arthritis: a phase 1 dose-escalation safety and tolerability study. Ann Rheum Dis. 2009; 68:1247-54. [PubMed: 18678578]

131. Brantly ML, Chulay JD, Wang L, et al. Sustained transgene expression despite T lymphocyte responses in a clinical trial of rAAV1-AAT gene therapy. Proc Natl Acad Sci U S A. 2009; 106:16363-8. [PubMed: 19706466]

132. Mendell JR, Rodino-Klapac LR, Rosales-Quintero X, et al. Limb-girdle muscular dystrophy type 2D gene therapy restores alpha-sarcoglycan and associated proteins. Ann Neurol. 2009; 66:2907. [PubMed: 19798725]

133. Stroes ES, Nierman MC, Meulenberg JJ, et al. Intramuscular administration of AAV1-lipoprotein lipase S447X lowers triglycerides in lipoprotein lipase-deficient patients. Arterioscler Thromb Vasc Biol. 2008; 28:2303-4. [PubMed: 18802015]

134. Mingozzi F, Meulenberg JJ, Hui DJ, et al. AAV-1-mediated gene transfer to skeletal muscle in humans results in dose-dependent activation of capsid-specific T cells. Blood. 2009; 114:207786. [PubMed: 19506302]

135. Lipskaia L, Chemaly ER, Hadri L, Lompre A-M, Hajjar RJ. Sarcoplasmic reticulum Ca ${ }^{2+}$ ATPase as a therapeutic target for heart failure. Exp Opin Biol Ther. 2010; 10:29-41. 
136. Limberis MP, Vandenberghe LH, Zhang L, Pickles RJ, Wilson JM. Transduction efficiencies of novel AAV vectors in mouse airway epithelium in vivo and human ciliated airway epithelium in vitro. Mol Ther. 2008; 17:294-301. [PubMed: 19066597]

137. Zincarelli C, Soltys S, Rengo G, Rabinowitz JE. Analysis of AAV serotypes 1-9 mediated gene expression and tropism in mice after systemic injection. Mol Ther. 2008; 16:1073-80. [PubMed: 18414476]

138. Cooper M, Nayak S, Hoffman BE, Terhorst C, Cao O, Herzog RW. Improved induction of immune tolerance to factor ix by hepatic aav-8 gene transfer. Hum Gene Ther. 2009; 20:767-76. [PubMed: 19309290]

139. Sondhi D, Hackett NR, Peterson DA, et al. Enhanced survival of the LINCL mouse following CLN2 gene transfer using the rh.10 rhesus macaque-derived adeno-associated virus vector. Mol Ther. 2006; 15:481-91. [PubMed: 17180118]

140. Mingozzi F, Maus MV, Hui DJ, et al. CD8+ T-cell responses to adeno-associated virus capsid in humans. Nat Med. 2007; 13:419-22. [PubMed: 17369837]

141. Gao GP, Alvira MR, Wang L, Calcedo R, Johnston J, Wilson JM. Novel adeno-associated viruses from rhesus monkeys as vectors for human gene therapy. Proc Natl Acad Sci U S A. 2002; 99:11854-9. [PubMed: 12192090]

142. Bantel-Schaal U, zur Hausen H. Characterization of the DNA of a defective human parvovirus isolated from a genital site. Virology. 1984; 134:52-63. [PubMed: 6324476]

143. Grimm D, Kay MA, Kleinschmidt JA. Helper virus-free, optically controllable, and two-plasmidbased production of adeno-associated virus vectors of serotypes 1 to 6 . Mol Ther. 2003; 7:83950. [PubMed: 12788658]

144. Mori S, Wang L, Takeuchi T, Kanda T. Two novel adeno-associated viruses from cynomolgus monkey: pseudotyping characterization of capsid protein. Virology. 2004; 330:375-83. [PubMed: 15567432]

145. Rutledge EA, Halbert CL, Russell DW. Infectious clones and vectors derived from adenoassociated virus (AAV) serotypes other than AAV type 2. J Virol. 1998; 72:309-19. [PubMed: 9420229]

146. Schmidt M, Grot E, Cervenka P, Wainer S, Buck C, Chiorini JA. Identification and characterization of novel adeno-associated virus isolates in ATCC virus stocks. J Virol. 2006; 80:5082-5. [PubMed: 16641301]

147. Grimm D, Kay MA. From virus evolution to vector revolution: use of naturally occurring serotypes of adeno-associated virus (AAV) as novel vectors for human gene therapy. Curr Gene Ther. 2003; 3:281-304. [PubMed: 12871018]

148. Chao H, Liu Y, Rabinowitz J, Li C, Samulski RJ, Walsh CE. Several log increase in therapeutic transgene delivery by distinct adeno-associated viral serotype vectors. Mol Ther. 2000; 2:619-23. [PubMed: 11124063]

149. Blankinship MJ, Gregorevic P, Allen JM, et al. Efficient transduction of skeletal muscle using vectors based on adeno-associated virus serotype 6. Mol Ther. 2004; 10:671-8. [PubMed: 15451451]

150. Gregorevic P, Blankinship MJ, Allen JM, et al. Systemic delivery of genes to striated muscles using adeno-associated viral vectors. Nat Med. 2004; 10:828-34. [PubMed: 15273747]

151. Pacak CA, Mah CS, Thattaliyath BD, et al. Recombinant adeno-associated virus serotype 9 leads to preferential cardiac transduction in vivo. Circ Res. 2006; 99:e3-9. [PubMed: 16873720]

152. Mori S, Takeuchi T, Enomoto Y, et al. Tissue distribution of cynomolgus adeno-associated viruses AAV10, AAV11, and AAVcy.7 in naturally infected monkeys. Arch Virol. 2008; 153:375-80. [PubMed: 18066635]

153. Rabinowitz JE, Bowles DE, Faust SM, Ledford JG, Cunningham SE, Samulski RJ. Crossdressing the virion: the transcapsidation of adeno-associated virus serotypes functionally defines subgroups. J Virol. 2004; 78:4421-32. [PubMed: 15078923]

154. Rabinowitz JE, Rolling F, Li C, et al. Cross-packaging of a single adeno-associated virus (AAV) type 2 vector genome into multiple AAV serotypes enables transduction with broad specificity. $\mathbf{J}$ Virol. 2002; 76:791-801. [PubMed: 11752169] 
155. Lerch TF, Xie Q, Ongley HM, Hare J, Chapman MS. Twinned crystals of adeno-associated virus serotype $3 \mathrm{~b}$ prove suitable for structural studies. Acta Crystallogr Sect F Struct Biol Cryst Commun. 2009; 65:177-83.

156. O'Donnell J, Taylor KA, Chapman MS. Adeno-associated virus-2 and its primary cellular receptor--Cryo-EM structure of a heparin complex. Virology. 2009; 385:434-43. [PubMed: 19144372]

157. Kern A, Schmidt K, Leder C, et al. Identification of a heparin-binding motif on adeno-associated virus type 2 capsids. J Virol. 2003; 77:11072-81. [PubMed: 14512555]

158. Shi X, Fang G, Shi W, Bartlett JS. Insertional mutagenesis at positions 520 and 584 of adenoassociated virus type 2 (AAV2) capsid gene and generation of AAV2 vectors with eliminated heparin-binding ability and introduced novel tropism. Hum Gene Ther. 2006; 17:353-61. [PubMed: 16544984]

159. Girod A, Ried M, Wobus C, et al. Genetic capsid modifications allow efficient re-targeting of adeno-associated virus type 2. Nat Med. 1999; 5:1438. [PubMed: 10581091]

160. Grifman M, Trepel M, Speece P, et al. Incorporation of tumor-targeting peptides into recombinant adeno-associated virus capsids. Mol Ther. 2001; 3:964-75. [PubMed: 11407911]

161. Shi W, Arnold GS, Bartlett JS. Insertional mutagenesis of the adeno-associated virus type 2 (AAV2) capsid gene and generation of AAV2 vectors targeted to alternative cell-surface receptors. Hum Gene Ther. 2001; 12:1697-711. [PubMed: 11560765]

162. Asokan A, Conway JC, Phillips JL, et al. Reengineering a receptor footprint of adeno-associated virus enables selective and systemic gene transfer to muscle. Nat Biotechnol. 2010; 28:79-82. [PubMed: 20037580]

163. Petrs-Silva H, Dinculescu A, Li Q, et al. High-efficiency transduction of the mouse retina by tyrosine-mutant AAV serotype vectors. Mol Ther. 2009; 17:463-71. [PubMed: 19066593]

164. Zhong L, Li B, Mah CS, et al. Next generation of adeno-associated virus 2 vectors: point mutations in tyrosines lead to high-efficiency transduction at lower doses. Proc Natl Acad Sci U S A. 2008; 105:7827-32. [PubMed: 18511559]

165. Zhang HG, Xie J, Dmitriev I, et al. Addition of six-His-tagged peptide to the $\mathrm{C}$ terminus of adeno-associated virus VP3 does not affect viral tropism or production. J Virol. 2002; 76:1202331. [PubMed: 12414944]

166. Zhong L, Li B, Jayandharan G, et al. Tyrosine-phosphorylation of AAV2 vectors and its consequences on viral intracellular trafficking and transgene expression. Virology. 2008; 381:194-202. [PubMed: 18834608]

167. Zhong $\mathrm{L}$, Zhao $\mathrm{W}, \mathrm{Wu}$ J, et al. A dual role of EGFR protein tyro-sine kinase signaling in ubiquitination of AAV2 capsids and viral second-strand DNA synthesis. Mol Ther. 2007; 15:1323-30. [PubMed: 17440440]

168. Yu CY, Yuan Z, Cao Z, et al. A muscle-targeting peptide displayed on AAV2 improves muscle tropism on systemic delivery. Gene Ther. 2009; 16:953-62. [PubMed: 19474807]

169. Liqun Wang R, McLaughlin T, Cossette T, et al. Recombinant AAV serotype and capsid mutant comparison for pulmonary gene transfer of alpha-1-antitrypsin using invasive and noninvasive delivery. Mol Ther. 2009; 17:81-7. [PubMed: 18941444]

170. Grimm D, Lee JS, Wang L, et al. In vitro and in vivo gene therapy vector evolution via multispecies interbreeding and retargeting of adeno-associated viruses. J Virol. 2008; 82:5887_ 911. [PubMed: 18400866]

171. White SJ, Nicklin SA, Buning H, et al. Targeted gene delivery to vascular tissue in vivo by tropism-modified adeno-associated virus vectors. Circulation. 2004; 109:513-9. [PubMed: 14732747]

172. White K, Buning H, Kritz A, et al. Engineering adeno-associated virus 2 vectors for targeted gene delivery to atherosclerotic lesions. Gene Ther. 2008; 15:443-51. [PubMed: 18004401]

173. Sellner L, Stiefelhagen M, Kleinschmidt JA, et al. Generation of efficient human blood progenitor-targeted recombinant adeno-associated viral vectors (AAV) by applying an AAV random peptide library on primary human hematopoietic progenitor cells. Exp Hematol. 2008; 36:957-64. [PubMed: 18495326] 
174. Stiefelhagen M, Sellner L, Kleinschmidt JA, et al. Application of a haematopoetic progenitor celltargeted adeno-associated viral (AAV) vector established by selection of an AAV random peptide library on a leukaemia cell line. Genet Vaccines Ther. 2008; 6:12. [PubMed: 18789140]

175. Muller OJ, Kaul F, Weitzman MD, et al. Random peptide libraries displayed on adeno-associated virus to select for targeted gene therapy vectors. Nat Biotechnol. 2003; 21:1040-6. [PubMed: 12897791]

176. Work LM, Buning H, Hunt E, et al. Vascular bed-targeted in vivo gene delivery using tropismmodified adeno-associated viruses. Mol Ther. 2006; 13:683-93. [PubMed: 16387552]

177. Nicklin SA, Buening H, Dishart KL, et al. Efficient and selective AAV2-mediated gene transfer directed to human vascular endothelial cells. Mol Ther. 2001; 4:174-81. [PubMed: 11545607]

178. Loiler SA, Conlon TJ, Song S, et al. Targeting recombinant adeno-associated virus vectors to enhance gene transfer to pancreatic islets and liver. Gene Ther. 2003; 10:1551-8. [PubMed: 12907946]

179. Perabo L, Buning H, Kofler DM, et al. In vitro selection of viral vectors with modified tropism: the adeno-associated virus display. Mol Ther. 2003; 8:151-7. [PubMed: 12842438]

180. Shi W, Bartlett JS. RGD inclusion in VP3 provides adeno-associated virus type 2 (AAV2)-based vectors with a heparan sul-fate-independent cell entry mechanism. Mol Ther. 2003; 7:515-25. [PubMed: 12727115]

181. Wu P, Xiao W, Conlon T, et al. Mutational analysis of the adeno-associated virus type 2 (AAV2) capsid gene and construction of AAV2 vectors with altered tropism. J Virol. 2000; 74:8635-47. [PubMed: 10954565]

182. Hida K, Won SY, Di Pasquale G, Hanes J, Chiorini JA, Ostermeier M. Sites in the AAV5 capsid tolerant to deletions and tandem duplications. Arch Biochem Biophys. 2010; 496(1):1-8. [PubMed: 20102698]

183. Boucas J, Lux K, Huber A, et al. Engineering adeno-associated virus serotype 2-based targeting vectors using a new insertion site-position 453-and single point mutations. J Gene Med. 2009; 11:1103-13. [PubMed: 19777441]

184. Warrington KH Jr. Gorbatyuk OS, Harrison JK, Opie SR, Zolotukhin S, Muzyczka N. Adenoassociated virus type 2 VP2 capsid protein is nonessential and can tolerate large peptide insertions at its N terminus. J Virol. 2004; 78:6595-609. [PubMed: 15163751]

185. Perabo L, Endell J, King S, et al. Combinatorial engineering of a gene therapy vector: directed evolution of adeno-associated virus. J Gene Med. 2006; 8:155-62. [PubMed: 16285001]

186. Waterkamp DA, Muller OJ, Ying Y, Trepel M, Kleinschmidt JA. Isolation of targeted AAV2 vectors from novel virus display libraries. J Gene Med. 2006; 8:1307-19. [PubMed: 16955542]

187. Michelfelder S, Lee MK, deLima-Hahn E, et al. Vectors selected from adeno-associated viral display peptide libraries for leukemia cell-targeted cytotoxic gene therapy. Exp Hematol. 2007; 35:1766-76. [PubMed: 17920758]

188. Michelfelder S, Kohlschutter J, Skorupa A, et al. Successful expansion but not complete restriction of tropism of adeno-associated vi rus by in vivo biopanning of random virus display peptide libraries. PLoS One. 2009; 4:e5122. [PubMed: 19357785]

189. Hauck B, Chen L, Xiao W. Generation and characterization of chimeric recombinant AAV vectors. Mol Ther. 2003; 7:419-25. [PubMed: 12668138]

190. Gigout L, Rebollo P, Clement N, et al. Altering AAV tropism with mosaic viral capsids. Mol Ther. 2005; 11:856-65. [PubMed: 15922956]

191. Stachler MD, Bartlett JS. Mosaic vectors comprised of modified AAV1 capsid proteins for efficient vector purification and targeting to vascular endothelial cells. Gene Ther. 2006; 13:92631. [PubMed: 16482202]

192. Maheshri N, Koerber JT, Kaspar BK, Schaffer DV. Directed evolution of adeno-associated virus yields enhanced gene delivery vectors. Nat Biotechnol. 2006; 24:198-204. [PubMed: 16429148]

193. Stemmer WP. DNA shuffling by random fragmentation and reassembly: in vitro recombination for molecular evolution. Proc Natl Acad Sci U S A. 1994; 91:10747-51. [PubMed: 7938023]

194. Crameri A, Raillard SA, Bermudez E, Stemmer WP. DNA shuffling of a family of genes from diverse species accelerates directed evolution. Nature. 1998; 391:288-91. [PubMed: 9440693] 
195. Li W, Asokan A, Wu Z, et al. Engineering and selection of shuffled AAV genomes: a new strategy for producing targeted biological nanoparticles. Mol Ther. 2008; 16:1252-60. [PubMed: 18500254]

196. Koerber JT, Jang JH, Schaffer DV. DNA shuffling of adeno-associated virus yields functionally diverse viral progeny. Mol Ther. 2008; 16:1703-9. [PubMed: 18728640]

197. Excoffon KJ, Koerber JT, Dickey DD, et al. Directed evolution of adeno-associated virus to an infectious respiratory virus. Proc Natl Acad Sci U S A. 2009; 106:3865-70. [PubMed: 19237554]

198. Li W, Zhang L, Johnson JS, et al. Generation of novel AAV variants by directed evolution for improved CFTR delivery to human ciliated airway epithelium. Mol Ther. 2009; 17:2067-77. [PubMed: 19603002]

199. Koerber JT, Klimczak R, Jang JH, Dalkara D, Flannery JG, Schaffer DV. Molecular evolution of adeno-associated virus for enhanced glial gene delivery. Mol Ther. 2009; 17:2088-95. [PubMed: 19672246]

200. Maguire CA, Gianni D, Meijer DH, et al. Directed evolution of adeno-associated virus for glioma cell transduction. J Neurooncol. 2009; 96:337-47. [PubMed: 19618115]

201. Yang L, Jiang J, Drouin LM, et al. A myocardium tropic adeno-associated virus (AAV) evolved by DNA shuffling and in vivo selection. Proc Natl Acad Sci U S A. 2009; 106:3946-51. [PubMed: 19234115]

202. Gray SJ, Blake BL, Criswell HE, Nicolson SC, Samulski RJ, McCown TJ. Directed Evolution of a Novel Adeno-associated Virus (AAV) Vector That Crosses the Seizure-compromised BloodBrain Barrier (BBB). Mol Ther. 2010; 18(3):570-5. [PubMed: 20040913]

203. Bartlett JS, Kleinschmidt J, Boucher RC, Samulski RJ. Targeted adeno-associated virus vector transduction of nonpermissive cells mediated by a bispecific F(ab'gamma) 2 antibody. Nat Biotechnol. 1999; 17:181-6. [PubMed: 10052356]

204. Arnold GS, Sasser AK, Stachler MD, Bartlett JS. Metabolic biotinylation provides a unique platform for the purification and targeting of multiple AAV vector serotypes. Mol Ther. 2006; 14:97-106. [PubMed: 16624620]

205. Ponnazhagan S, Mahendra G, Kumar S, Thompson JA, Castillas M Jr. Conjugate-based targeting of recombinant adeno-associated virus type 2 vectors by using avidin-linked ligands. J Virol. 2002; 76:12900-7. [PubMed: 12438615]

206. Stachler MD, Chen I, Ting AY, Bartlett JS. Site-specific modification of AAV vector particles with biophysical probes and targeting ligands using biotin ligase. Mol Ther. 2008; 16:1467-73. [PubMed: 18560418]

207. Carlisle RC, Benjamin R, Briggs SS, et al. Coating of adeno-associated virus with reactive polymers can ablate virus tropism, enable retargeting and provide resistance to neutralising antisera. J Gene Med. 2008; 10:400-11. [PubMed: 18220318]

208. Lee GK, Maheshri N, Kaspar B, Schaffer DV. PEG conjugation moderately protects adenoassociated viral vectors against antibody neutralization. Biotechnol Bioeng. 2005; 92:24-34. [PubMed: 15937953]

209. Fein DE, Limberis MP, Maloney SF, Heath JM, Wilson JM, Diamond SL. Cationic lipid formulations alter the in vivo tropism of AAV2/9 vector in lung. Mol Ther. 2009; 17:2078-87. [PubMed: 19638960]

210. Sun X, Pawlyk B, Xu X, et al. Gene therapy with a promoter targeting both rods and cones rescues retinal degeneration caused by AIPL1 mutations. Gene Ther. 17:117-31. [PubMed: 19710705]

211. Li Q, Timmers AM, Guy J, Pang J, Hauswirth WW. Cone-specific expression using a human red opsin promoter in recombinant AAV. Vision Res. 2008; 48:332-8. [PubMed: 17905404]

212. Khani SC, Pawlyk BS, Bulgakov OV, et al. AAV-mediated expression targeting of rod and cone photoreceptors with a human rhodopsin kinase promoter. Invest Ophthalmol Vis Sci. 2007; 48:3954-61. [PubMed: 17724172]

213. Glushakova LG, Timmers AM, Pang J, Teusner JT, Hauswirth WW. Human blue-opsin promoter preferentially targets reporter gene expression to rat s-cone photoreceptors. Invest Ophthalmol Vis Sci. 2006; 47:3505-13. [PubMed: 16877422] 
214. Kyo S, Kanaya T, Takakura M, Tanaka M, Inoue M. Human telomerase reverse transcriptase as a critical determinant of telom-erase activity in normal and malignant endometrial tissues. Int $\mathbf{J}$ Cancer. 1999; 80:60-3. [PubMed: 9935231]

215. Lin T, Huang X, Gu J, et al. Long-term tumor-free survival from treatment with the GFP-TRAIL fusion gene expressed from the hTERT promoter in breast cancer cells. Oncogene. 2002; 21:8020-8. [PubMed: 12439752]

216. Liu J, Zou WG, Lang MF, et al. Cancer-specific killing by the CD suicide gene using the human telomerase reverse transcriptase promoter. Int J Oncol. 2002; 21:661-6. [PubMed: 12168115]

217. Wang Y, Huang F, Cai H, Zhong S, Liu X, Tan WS. Potent antitumor effect of TRAIL mediated by a novel adeno-associated viral vector targeting to telomerase activity for human hepatocellular carcinoma. J Gene Med. 2008; 10:518-26. [PubMed: 18338833]

218. Zhang Y, Ma H, Zhang J, Liu S, Liu Y, Zheng D. AAV-mediated TRAIL gene expression driven by hTERT promoter suppressed human hepatocellular carcinoma growth in mice. Life Sci. 2008; 82:1154-61. [PubMed: 18485417]

219. He LF, Wang YG, Xiao T, et al. Suppression of cancer growth in mice by adeno-associated virus vector-mediated IFN-beta expression driven by hTERT promoter. Cancer Lett. 2009; 286:196205. [PubMed: 19564073]

220. Sieger S, Jiang S, Kleinschmidt J, et al. Tumor-specific gene expression using regulatory elements of the glucose transporter iso-form 1 gene. Cancer Gene Ther. 2004; 11:41-51. [PubMed: 14681725]

221. Muller OJ, Leuchs B, Pleger ST, et al. Improved cardiac gene transfer by transcriptional and transductional targeting of adeno-associated viral vectors. Cardiovasc Res. 2006; 70:70-8. [PubMed: 16448634]

222. Aldrich WA, Ren C, White AF, et al. Enhanced transduction of mouse bone marrow-derived dendritic cells by repetitive infection with self-complementary adeno-associated virus 6 combined with immunostimulatory ligands. Gene Ther. 2006; 13:29-39. [PubMed: 16136165]

223. Herzog RW, Hagstrom JN, Kung SH, et al. Stable gene transfer and expression of human blood coagulation factor IX after intramuscular injection of recombinant adeno-associated virus. Proc Natl Acad Sci U S A. 1997; 94:5804-9. [PubMed: 9159155]

224. Herzog RW, Mount JD, Arruda VR, High KA, Lothrop CD Jr. Muscle-directed gene transfer and transient immune suppression result in sustained partial correction of canine hemophilia $\mathrm{B}$ caused by a null mutation. Mol Ther. 2001; 4:192-200. [PubMed: 11545609]

225. Liu Y, Chiriva-Internati M, You C, et al. Use and specificity of breast cancer antigen/milk protein BA46 for generating anti-self-cytotoxic T lymphocytes by recombinant adeno-associated virusbased gene loading of dendritic cells. Cancer Gene Ther. 2005; 12:304-12. [PubMed: 15565181]

226. Sarukhan A, Camugli S, Gjata B, von Boehmer H, Danos O, Jooss K. Successful interference with cellular immune responses to immunogenic proteins encoded by recombinant viral vectors. J Virol. 2001; 75:269-77. [PubMed: 11119597]

227. Sarukhan A, Soudais C, Danos O, Jooss K. Factors influencing cross-presentation of non-self antigens expressed from recombinant adeno-associated virus vectors. J Gene Med. 2001; 3:260 70. [PubMed: 11437331]

228. Veron P, Allo V, Riviere C, Bernard J, Douar AM, Masurier C. Major subsets of human dendritic cells are efficiently transduced by self-complementary adeno-associated virus vectors 1 and 2 . J Virol. 2007; 81:5385-94. [PubMed: 17314166]

229. Wuensch SA, Pierce RH, Crispe IN. Local intrahepatic CD8+ T cell activation by a non-selfantigen results in full functional differentiation. J Immunol. 2006; 177:1689-97. [PubMed: 16849478]

230. Zhang TP, Jin DY, Wardrop RM, et al. Transgene expression levels and kinetics determine risk of humoral immune response modeled in factor IX knockout and missense mutant mice. Gene Ther. 2007; 14:429-40. [PubMed: 17066096]

231. Blacklow NR, Hoggan MD, Rowe WP. Serologic evidence for human infection with adenovirusassociated viruses. J Natl Cancer Inst. 1968; 40:319-27. [PubMed: 4295610] 
232. Mayor HD, Drake S, Stahmann J, Mumford DM. Antibodies to adeno-associated satellite virus and herpes simplex in sera from cancer patients and normal adults. Am J Obstet Gynecol. 1976; 126:100-4. [PubMed: 183503]

233. Halbert CL, Miller AD, McNamara S, et al. Prevalence of neutralizing antibodies against adenoassociated virus (AAV) types 2, 5, and 6 in cystic fibrosis and normal populations: Implications for gene therapy using AAV vectors. Hum Gene Ther. 2006; 17:440-7. [PubMed: 16610931]

234. Tobiasch E, Rabreau M, Geletneky K, et al. Detection of adeno-associated virus DNA in human genital tissue and in material from spontaneous abortion. J Med Virol. 1994; 44:215-22. [PubMed: 7852963]

235. Erles K, Sebokova P, Schlehofer JR. Update on the prevalence of serum antibodies (IgG and IgM) to adeno-associated virus (AAV). J Med Virol. 1999; 59:406-11. [PubMed: 10502275]

236. Calcedo R, Vandenberghe LH, Gao G, Lin J, Wilson JM. Worldwide epidemiology of neutralizing antibodies to adeno-associated viruses. J Infect Dis. 2009; 199:381-90. [PubMed: 19133809]

237. Sprecher-Goldberger S, Thiry L, Lefebvre N, Dekegel D, de Halleux F. Complement-fixation antibodies to adenovirus-associated viruses, cytomegaloviruses and herpes simplex viruses in patients with tumors and in control individuals. Am J Epidemiol. 1971; 94:351-8. [PubMed: 4331027]

238. Mingozzi F, Maus MV, Hui DJ, et al. CD8(+) T-cell responses to adeno-associated virus capsid in humans. Nat Med. 2007; 13:419-22. [PubMed: 17369837]

239. Pulendran B, Ahmed R. Translating innate immunity into immunological memory: implications for vaccine development. Cell. 2006; 124:849-63. [PubMed: 16497593]

240. Zaiss AK, Cotter MJ, White LR, et al. Complement is an essential component of the immune response to adeno-associated virus vectors. J Virol. 2008; 82:2727-40. [PubMed: 18199646]

241. Zaiss AK, Liu Q, Bowen GP, Wong NC, Bartlett JS, Muruve DA. Differential activation of innate immune responses by adenovirus and adeno-associated virus vectors. J Virol. 2002; 76:4580-90. [PubMed: 11932423]

242. Zhu J, Huang X, Yang Y. The TLR9-MyD88 pathway is critical for adaptive immune responses to adeno-associated virus gene therapy vectors in mice. J Clin Invest. 2009; 119:2388-98. [PubMed: 19587448]

243. Moskalenko M, Chen L, van Roey M, et al. Epitope mapping of human anti-adeno-associated virus type 2 neutralizing antibodies: implications for gene therapy and virus structure. J Virol. 2000; 74:1761-6. [PubMed: 10644347]

244. Wobus CE, Hugle-Dorr B, Girod A, Petersen G, Hallek M, Klein-schmidt JA. Monoclonal antibodies against the adeno-associated virus type 2 (AAV-2) capsid: epitope mapping and identification of capsid domains involved in AAV-2-cell interaction and neutralization of AAV-2 infection. J Virol. 2000; 74:9281-93. [PubMed: 10982375]

245. Sabatino DE, Mingozzi F, Hui DJ, et al. Identification of mouse AAV capsid-specific CD8+ T cell epitopes. Mol Ther. 2005; 12:1023-33. [PubMed: 16263332]

246. Mays LE, Wilson JM. Identification of the murine AAVrh32.33 capsid-specific CD8+ T cell epitopes. J Gene Med. 2009; 11:1095-102. [PubMed: 19777488]

247. Chen J, Wu Q, Yang P, Hsu HC, Mountz JD. Determination of specific CD4 and CD8 T cell epitopes after AAV2- and AAV8-hF.IX gene therapy. Mol Ther. 2006; 13:260-9. [PubMed: 16324888]

248. Murphy SL, Li H, Mingozzi F, et al. Diverse IgG subclass responses to adeno-associated virus infection and vector administration. J Med Virol. 2009; 81:65-74. [PubMed: 19031458]

249. Madsen D, Cantwell ER, O'Brien T, Johnson PA, Mahon BP. Adeno-associated virus serotype 2 induces cell-mediated immune responses directed against multiple epitopes of the capsid protein VP1. J Gen Virol. 2009; 90:2622-33. [PubMed: 19641045]

250. Mingozzi F, High KA. Immune responses to AAV in clinical trials. Curr Gene Ther. 2007; 7:316-24. [PubMed: 17979678]

251. Li C, Hirsch M, Asokan A, et al. Adeno-associated virus type 2 (AAV2) capsid-specific cytotoxic T lymphocytes eliminate only vector-transduced cells coexpressing the AAV2 capsid in vivo. J Virol. 2007; 81:7540-7. [PubMed: 17475652] 
252. Wang Z, Allen JM, Riddell SR, et al. Immunity to adeno-associated virus-mediated gene transfer in a random-bred canine model of Duchenne muscular dystrophy. Hum Gene Ther. 2007; 18:1826. [PubMed: 17176210]

253. Mount JD, Herzog RW, Tillson DM, et al. Sustained phenotypic correction of hemophilia B dogs with a factor IX null mutation by liver-directed gene therapy. Blood. 2002; 99:2670-6. [PubMed: 11929752]

254. Nathwani AC, Davidoff AM, Hanawa H, et al. Sustained high-level expression of human factor IX (hFIX) after liver-targeted delivery of recombinant adeno-associated virus encoding the hFIX gene in rhesus macaques. Blood. 2002; 100:1662-9. [PubMed: 12176886]

255. Le HT, Yu QC, Wilson JM, Croyle MA. Utility of PEGylated recombinant adeno-associated viruses for gene transfer. J Control Release. 2005; 108:161-77. [PubMed: 16125817]

256. Xiao W, Chirmule N, Berta SC, McCullough B, Gao G, Wilson JM. Gene therapy vectors based on adeno-associated virus type 1. J Virol. 1999; 73:3994-4003. [PubMed: 10196295]

257. Halbert CL, Rutledge EA, Allen JM, Russell DW, Miller AD. Repeat transduction in the mouse lung by using adeno-associated virus vectors with different serotypes. J Virol. 2000; 74:1524-32. [PubMed: 10627564]

258. Hildinger M, Auricchio A, Gao G, Wang L, Chirmule N, Wilson JM. Hybrid vectors based on adeno-associated virus serotypes 2 and 5 for muscle-directed gene transfer. J Virol. 2001; 75:6199-203. [PubMed: 11390622]

259. Riviere C, Danos O, Douar AM. Long-term expression and repeated administration of AAV type 1,2 and 5 vectors in skeletal muscle of immunocompetent adult mice. Gene Ther. 2006; 13:1300-8. [PubMed: 16688207]

260. Sandalon Z, Bruckheimer EM, Lustig KH, Rogers LC, Peluso RW, Burstein H. Secretion of a TNFR:Fc fusion protein following pulmonary administration of pseudotyped adeno-associated virus vectors. J Virol. 2004; 78:12355-65. [PubMed: 15507622]

261. Vandendriessche T, Thorrez L, Acosta-Sanchez A, et al. Efficacy and safety of adeno-associated viral vectors based on serotype 8 and 9 vs. lentiviral vectors for hemophilia B gene therapy. J Thromb Haemost. 2007; 5:16-24. [PubMed: 17002653]

262. Mays LE, Vandenberghe LH, Xiao R, et al. Adeno-associated virus capsid structure drives CD4dependent CD8+ T cell response to vector encoded proteins. J Immunol. 2009; 182:6051-60. [PubMed: 19414756]

263. Huttner NA, Girod A, Perabo L, et al. Genetic modifications of the adeno-associated virus type 2 capsid reduce the affinity and the neutralizing effects of human serum antibodies. Gene Ther. 2003; 10:2139-47. [PubMed: 14625569]

264. Maersch S, Huber A, Buning H, Hallek M, Perabo L. Optimization of stealth adeno-associated virus vectors by randomization of immunogenic epitopes. Virology. 2010; 397:167-75. [PubMed: 19926109]

265. Vandenberghe LH, Wang L, Somanathan S, et al. Heparin binding directs activation of T cells against adeno-associated virus serotype 2 capsid. Nat Med. 2006; 12:967-71. [PubMed: 16845388]

266. Li C, Goudy K, Hirsch M, et al. Cellular immune response to cryptic epitopes during therapeutic gene transfer. Proc Natl Acad Sci U S A. 2009; 106:10770-4. [PubMed: 19541644]

267. Brockstedt DG, Podsakoff GM, Fong L, Kurtzman G, Mueller-Ruchholtz W, Engleman EG. Induction of immunity to antigens expressed by recombinant adeno-associated virus depends on the route of administration. Clin Immunol. 1999; 92:67-75. [PubMed: 10413654]

268. Xiao W, Chirmule N, Schnell MA, Tazelaar J, Hughes JV, Wilson JM. Route of administration determines induction of T-cell-independent humoral responses to adeno-associated virus vectors. Mol Ther. 2000; 1:323-9. [PubMed: 10933950]

269. Ge Y, Powell S, Van Roey M, McArthur JG. Factors influencing the development of an antifactor IX (FIX) immune response following administration of adeno-associated virus-FIX. Blood. 2001; 97:3733-7. [PubMed: 11389010]

270. Wang L, Cao O, Swalm B, Dobrzynski E, Mingozzi F, Herzog RW. Major role of local immune responses in antibody formation to factor IX in AAV gene transfer. Gene Ther. 2005; 12:145364. [PubMed: 15889137] 
271. Wang L, Dobrzynski E, Schlachterman A, Cao O, Herzog RW. Systemic protein delivery by muscle-gene transfer is limited by a local immune response. Blood. 2005; 105:4226-34. [PubMed: 15713796]

272. Cao O, Dobrzynski E, Wang L, et al. Induction and role of regulatory CD4+CD25+ T cells in tolerance to the transgene product following hepatic in vivo gene transfer. Blood. 2007; 110:1132-40. [PubMed: 17438084]

273. Dobrzynski E, Mingozzi F, Liu YL, et al. Induction of antigen-specific CD4+ T-cell anergy and deletion by in vivo viral gene transfer. Blood. 2004; 104:969-77. [PubMed: 15105293]

274. Gross DA, Leboeuf M, Gjata B, Danos O, Davoust J. CD4+CD25+ regulatory T cells inhibit immune-mediated transgene rejection. Blood. 2003; 102:4326-8. [PubMed: 12893754]

275. Lin SW, Hensley SE, Tatsis N, Lasaro MO, Ertl HC. Recombinant adeno-associated virus vectors induce functionally impaired trans-gene product-specific CD8+ T cells in mice. J Clin Invest. 2007; 117:3958-70. [PubMed: 18008010]

276. Mingozzi F, Liu YL, Dobrzynski E, et al. Induction of immune tolerance to coagulation factor IX antigen by in vivo hepatic gene transfer. J Clin Invest. 2003; 111:1347-56. [PubMed: 12727926]

277. Velazquez VM, Bowen DG, Walker CM. Silencing of T lymphocytes by antigen-driven programmed death in recombinant adeno-associated virus vector-mediated gene therapy. Blood. 2009; 113:538-45. [PubMed: 18566327]

278. Li Q, Miller R, Han PY, et al. Intraocular route of AAV2 vector administration defines humoral immune response and therapeutic potential. Mol Vis. 2008; 14:1760-9. [PubMed: 18836574]

279. Mastakov MY, Baer K, Symes CW, Leichtlein CB, Kotin RM, During MJ. Immunological aspects of recombinant adeno-associated virus delivery to the mammalian brain. J Virol. 2002; 76:8446-54. [PubMed: 12134047]

280. Peden CS, Manfredsson FP, Reimsnider SK, et al. Striatal readministration of rAAV vectors reveals an immune response against AAV2 capsids that can be circumvented. Mol Ther. 2009; 17:524-37. [PubMed: 19142181]

281. Sabatino DE, Mackenzie TC, Peranteau W, et al. Persistent expression of hF.IX After tolerance induction by in utero or neonatal administration of AAV-1-F.IX in hemophilia B mice. Mol Ther. 2007; 15:1677-85. [PubMed: 17565352]

282. Halbert CL, Standaert TA, Wilson CB, Miller AD. Successful readministration of adenoassociated virus vectors to the mouse lung requires transient immunosuppression during the initial exposure. J Virol. 1998; 72:9795-805. [PubMed: 9811715]

283. Manning WC, Zhou S, Bland MP, Escobedo JA, Dwarki V. Transient immunosuppression allows transgene expression following readministration of adeno-associated viral vectors. Hum Gene Ther. 1998; 9:477-85. [PubMed: 9525309]

284. Wang Z, Kuhr CS, Allen JM, et al. Sustained AAV-mediated dystrophin expression in a canine model of Duchenne muscular dystrophy with a brief course of immunosuppression. Mol Ther. 2007; 15:1160-6. [PubMed: 17426713]

285. Hirsch ML, Agbandje-McKenna M, Samulski RJ. Little vector, big gene transduction: fragmented genome reassembly of adeno-associated virus. Mol Ther. 2010; 18:6-8. [PubMed: 20048740]

286. Hewitt FC, Li C, Gray SJ, Cockrell S, Washburn M, Samulski RJ. Reducing the risk of adenoassociated virus (AAV) vector mobilization with AAV type 5 vectors. J Virol. 2009; 83:3919-29. [PubMed: 19211760]

287. Reddy VS, Natarajan P, Okerberg B, et al. Virus Particle Explorer (VIPER), a website for virus capsid structures and their computational analyses. J Virol. 2001; 75:11943-7. [PubMed: 11711584] 

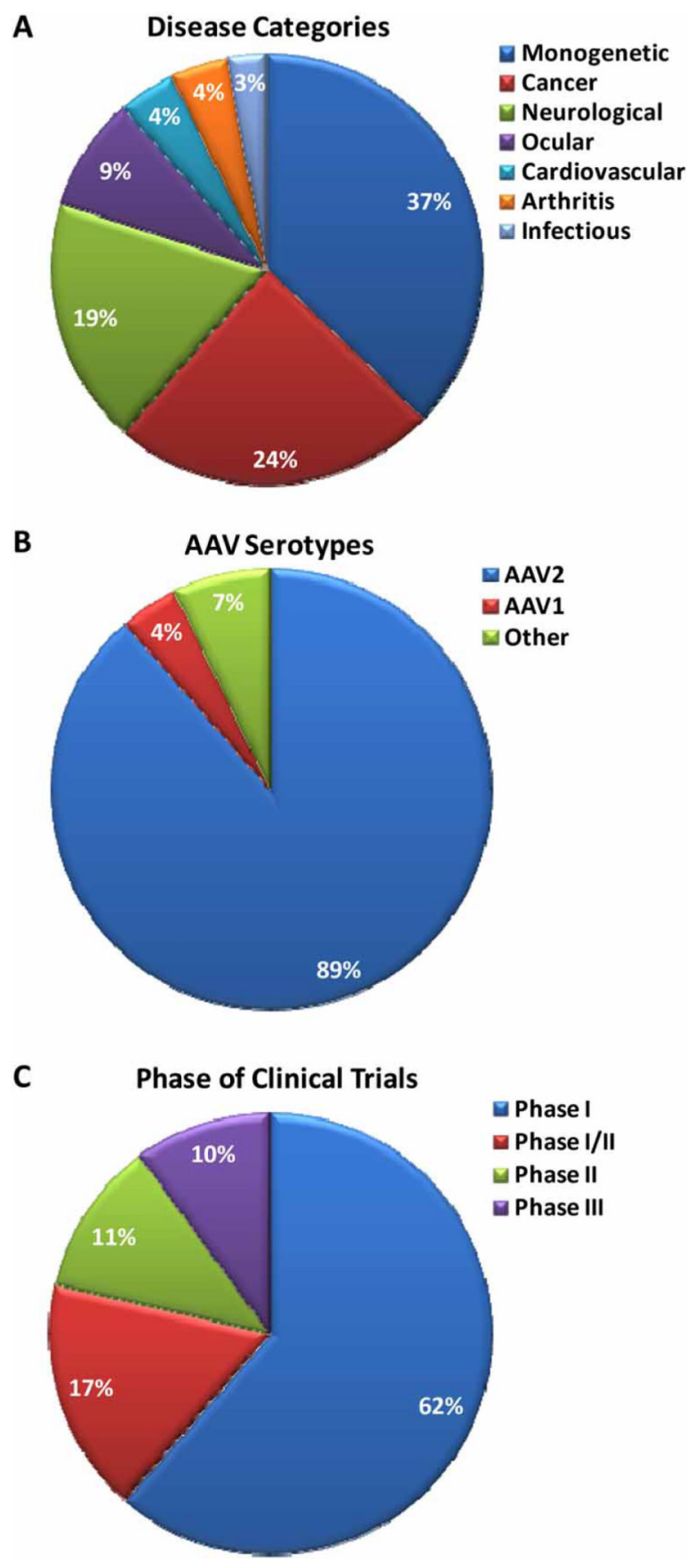

Fig. (1).

Past and Current Clinical Trials Utilizing rAAV. The percentage of clinical trials using rAAV (A) in different categories of disease, $(\mathbf{B})$ in different phases, and $(\mathbf{C})$ using capsids of different serotypes of AAV. Other serotypes includes AAV8, AAV2.5, AAV6, and AAVrh. 10. Clinical trial data was compiled from the Gene Therapy Clinical Trials Worldwide Database (http://www.wiley.co.uk/genetherapy/clinical). 

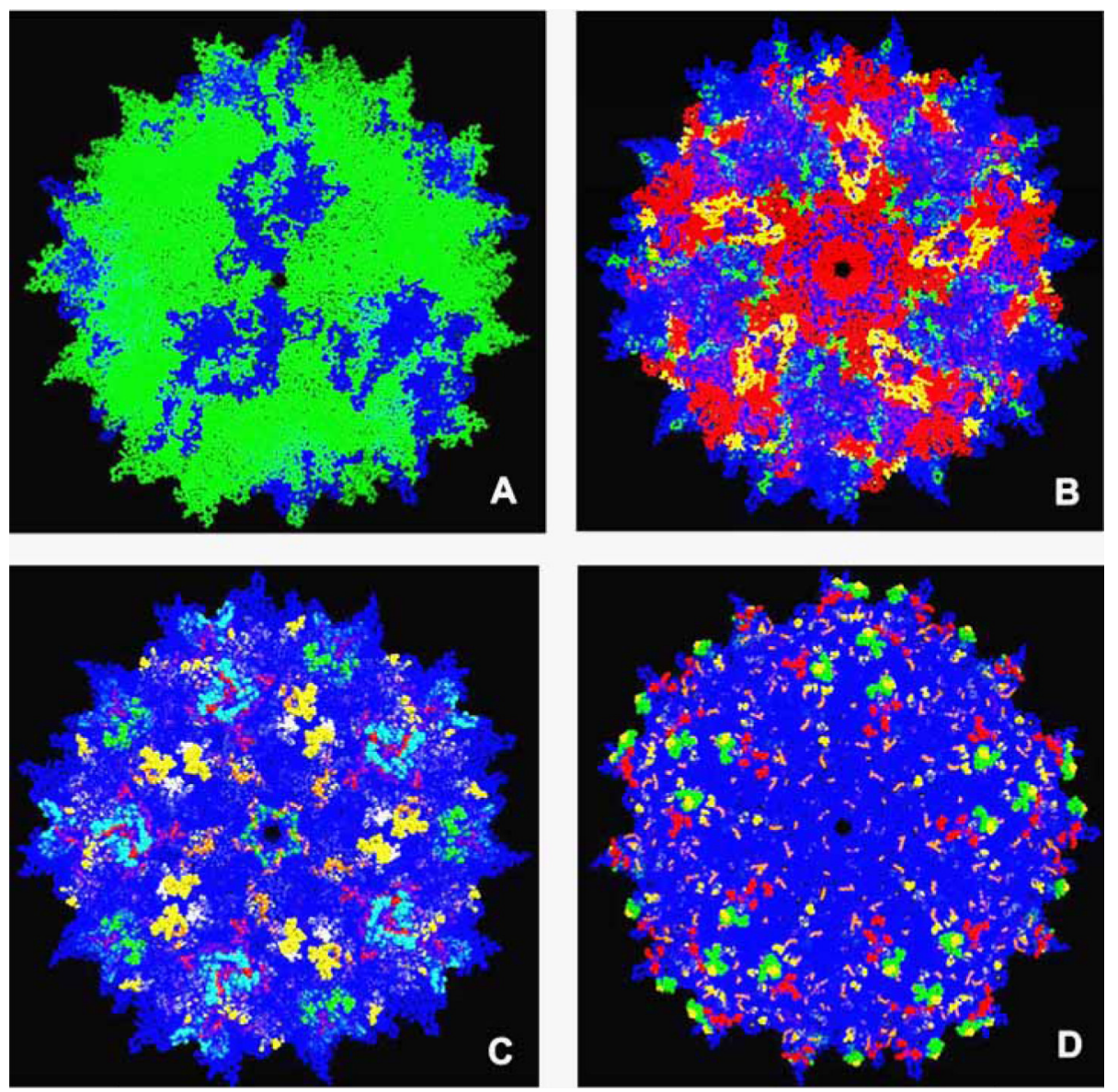

Fig. (2).

Representation of various strategies to modify AAV capsids for tissue targeting and immune evasion. A. Example of a mosaic virus, where plasmids encoding for the capsids of two different serotypes are combined in a molar ratio of 1:5 , AAVx; $\bullet$, AAVy. B. Example of a chimeric virus (adapted from chimeric-1829 [195]). @, AAV1; ๑, AAV8; ๑, AAV2; , AAV9. C. Combinatorial representation of human and murine antibody and cell mediated epitopes of AAV serotypes displayed on an AAV2 background. ๑, ๑, ๑, [243]; , [246]; ○, [244]; , [238]; , [245]; @, [247]; @, AAV2 background. D. Capsid modifications rendering ability to escape neutralization displayed on an AAV2 background. $\bullet$, [264]; [162]; , [208]; , [263];, AAV2 background. The available structure of the AAV2 monomer (PDB accession no. 1LP3) was supplied as a template for capsid generation. Capsid features were rendered using PyMOL (http://pymol.sourceforge.net). For figure 2a, monomers were structurally aligned to an AAV2 template using PyMOL. For figure 2b-d, AAV2 models were generated with VIPER [287]. 